\title{
Arquitectura y urbanismo de Machaquilá, Petén, Guatemala
}

\author{
Andrés Ciudad Ruiz y Jesús AdÁnez Pavón \\ Depto. de Historia de América II (Antropología de América) \\ Universidad Complutense de Madrid \\ andresci@ghis.ucm.es adanez@ghis.ucm.es
}

Recibido: 15 de octubre de 2010

Aceptado: 19 de octubre de 2010

\section{RESUMEN}

El artículo analiza la arquitectura de la ciudad maya de Machaquilá (Petén, Guatemala) a través de la descripción y discusión de las técnicas constructivas, los tipos de edificios y conjuntos y la decoración adosada a los edificios, añadiendo asimismo un análisis de su diseño urbano desde la perspectiva de su relación con el ritual. En todos estos aspectos se evalúan las diferencias entre el Clásico Tardío y el Terminal, así como la influencia de dos tradiciones regionales vecinas: el Sureste de Petén y el área del río Pasión.

Palabras clave: Arquitectura maya, urbanismo maya, Clásico Tardío, Clásico Terminal, Petén, Machaquilá.

\section{Architecture and Urbanism of Machaquilá, Petén, Guatemala}

\begin{abstract}
The article analyzes the architecture of the Maya city of Machaquilá (Peten, Guatemala) through the description and discussion of construction techniques, types of buildings and complexes, and decoration attached to buildings, also adding an analysis of the urban design from the perspective of its relationship to ritual. In these respects the differences between Late and Terminal Classic Periods, and the influence from two neighboring regional traditions -South East Petén and Pasión River area- are evaluated.
\end{abstract}

Key words: Maya architecture, Maya urbanism, Late Classic Period, Terminal Classic Period, Petén, Machaquilá.

Sumario: 1. Organización general. 2. Materiales y técnicas de construcción. 3. Tipos de construcciones. 4. Decoración. 5. Diseño urbanístico. 6. Conclusiones. 7. Referencias bibliográficas.

La abundancia y el, en términos generales, excelente estado de conservación con que se presenta la arquitectura en el registro cultural de las Tierras Bajas mayas, hacen que este rasgo constituya una de las fuentes de conocimiento más importante sobre esta cultura del pasado mesoamericano. La arquitectura se ve acompañada, además, por una abundante y variada información iconográfica, epigráfica y contextual acerca de las grandes construcciones que conforman el paisaje construido, fuentes que completan de manera bastante satisfactoria nuestra visión sobre las características más relevantes de los edificios que alojaron, utilizaron y planificaron los dirigentes mayas (Webster 1998; véase, en general, Houston [ed.] 1998). Tales características han hecho que las construcciones mayas y su organización en el paisaje hayan recibido la atención de los investigadores desde los inicios de la investigación sobre esta sofisticada civilización. Es, por otra parte, uno de los rasgos que los arqueólogos han utilizado

Esta investigación se ha realizado en el marco del proyecto «La entidad política de Machaquilá (Guatemala) durante el Clásico Tardío y el Clásico Terminal», el cual ha sido financiado sucesivamente por el Ministerio de Cultura (años 2001 y 2002) y por el Ministerio de Ciencia y Tecnología y el Ministerio de Educación ( ${ }^{\circ}$ de Referencia: BHA 2002-03729) entre 2003 y 2005. 
de manera tradicional para generar y comprobar hipótesis acerca de la naturaleza de la sociedad y la cultura maya, y de manera especial de la cultura de la elite.

Este interés ha derivado en un buen conocimiento del medio construido maya o, dicho de otro modo, del conjunto de modificaciones que sus agentes hicieron sobre su paisaje circundante. Pero a pesar de ello, y de los estudios y las síntesis que sobre la arquitectura maya se han realizado a lo largo de más de 150 años de investigación (véase Pollock 1980; Gendrop 1983; Andrews 1994, 1995-99), la realidad es que aún existen zonas en que las formas arquitectónicas, las características estilísticas, la conjunción en el espacio de estas formas y la ausencia o presencia de determinados rasgos carecen de una explicación suficiente.

Es el caso de Machaquilá y su entorno regional. Rescatada para el conocimiento científico a partir de 1961 por los estudios de I. Graham (1967), la ciudad apenas si ha sido objeto de análisis desde estos esfuerzos pioneros. Los trabajos realizados en el entorno regional en que se emplaza este centro por parte del Atlas Arqueológico de Guatemala (Laporte, Mejía y Chocón 2005) han aportado el conocimiento de la existencia de un importante número de sitios, cuyas características arquitectónicas, no obstante, están aún por definir en muchos casos; será la evidencia obtenida en estos sitios, junto a la derivada de nuestro programa de investigación en la propia Machaquilá (véase Ciudad et al., en este volumen), así como la procedente de centros cercanos importantes al oeste de ella, como Cancuén -en donde se viene desarrollando el Proyecto Arqueológico Cancuén, dirigido por Arthur Demarest- y Ceibal -en donde, además de las investigaciones a cargo de la Universidad de Harvard en los años sesenta, trabaja desde 2006 el Proyecto Arqueológico Ceibal-Petexbatún, dirigido por Takeshi Inomata, si bien centrado en el periodo Preclásico-, la que nos debe permitir contextualizar los aspectos más relevantes de la arquitectura de Machaquilá. Sin duda su estudio regional, considerando tanto el Sureste de Petén como su entorno más occidental, es el que nos habrá de proporcionar un conocimiento detallado sobre este particular.

La información epigráfica obtenida en Machaquilá sostiene que la ciudad fue fundada en el Clásico Tardío, quizás a finales del siglo VII, y que su ocupación apenas si superó la mitad del siglo IX (Ciudad y Lacadena 2006; 2008). Esta conclusión queda avalada por la evidencia arqueológica general del sitio, tanto en lo que se refiere a su cultura material mueble, como a su arquitectura y escultura. Es, en consecuencia, una etapa en la que el diseño urbano y arquitectónico de las Tierras Bajas mayas estaba ya plena y definitivamente elaborado; incluso algunos de sus preceptos más arraigados habían sido ya abandonados o comenzaban a decaer en su importancia. Machaquilá se instala en una región de transición en lo que se refiere a patrones urbanos y culturales: aunque no respeta algunos de los preceptos que son norma en la región Sureste de Petén - por ejemplo, carece de conjunto de tipo Grupo E, de juego de pelota o de conjuntos de tipo Acrópolis-, mantiene afiliaciones cerámicas y ciertos aspectos estilísticos en la escultura y la decoración arquitectónica que son definitorios de esa zona; pero además se inscribe en una tradición de relaciones políticas y, quizás, de origen anclada en la región del Pasión, y mantiene rasgos de decoración arquitectónica, de estilo escultórico y de sistema constructivo propios de este territorio (Ciudad y Lacadena 2008).

Quizás este carácter integrador de tradiciones distintas tenga relación con su posición estratégica respecto de la comunicación existente entre el Sureste de Petén y las 
Montañas Mayas, por el este, y el Pasión y el Usumacinta, por el oeste. Esta idiosincrasia arquitectónica tiene su paralelo, a juzgar por lo que Just (2002) ha puesto de manifiesto en un trabajo reciente, en varias características estilísticas e iconográficas que manifiestan las estelas de Machaquilá en comparación con las de centros arqueológicos emplazados al oeste -Dos Pilas y Cancuén, por ejemplo- y al noreste de ella -Ixtutz y Naranjo, por ejemplo-. Esta posición fronteriza entre dos áreas de tradición cultural diferenciada quizás fuera seleccionada de manera deliberada debido a acontecimientos de tipo histórico y político (Ciudad y Lacadena 2006), pero sin duda se nutrió de su ubicación favorable en la mencionada vía de comunicación, que fue definida por el curso del río Machaquilá y sus tributarios.

\section{Organización general}

La disposición de Machaquilá fue decidida y, en cierto modo, estuvo limitada por el terreno elegido para su emplazamiento, constreñido por el norte por un brazo del río homónimo, más allá del cual no hemos podido localizar asentamiento alguno, ni urbano ni doméstico. El sur de este brazo está formado por una secuencia de colinas dolomíticas que dejan entre sí pequeñas planicies y zonas de bajos, un área que se va abriendo y disminuyendo en altura por el oeste, en dirección al río Pasión en que tributa el río Machaquilá (véase Ciudad et al., en este volumen: fig. 1). Esta zona baja está ocupada en algunos tramos por pantanos y ciénagas, que alternan en las márgenes del río Chilar con buenas tierras cultivables; en su conjunto se trata de un área con recursos naturales limitados. El núcleo administrativo ocupó una de esas reducidas planicies, bien situado para su defensa y con fácil acceso al agua, a la tierra cultivable y a la caza y la extracción de materias primas en el bosque que ocupaba las mencionadas colinas circundantes.

Este terreno fue acondicionado, sobre todo en su zona norte, para construir la Plaza F, y al este para alojar las Plazas A, B y H y sus edificios; también se realizaron labores importantes de acondicionamiento en el caso de la Plaza E. Sin embargo, la mitad sur del centro se organizó en un terreno más abierto y bajo, y no requirió de tan enorme gasto energético para su ubicación. La ciudad se abre por el suroeste, y de la Plaza D -más exactamente del Grupo 22, situado en su extremo meridional- parten sendas calzadas que conducen a grupos terminales que conectan la zona urbana con los grupos domésticos, directamente relacionados con las tierras cultivables. Estas condiciones naturales, junto a su fundación tardía a la conclusión del siglo VII, se encuentran en el origen de que el diseño del sitio fuera compacto, no excediendo los $250 \mathrm{~m}$ en dirección este-oeste y algo menos de $200 \mathrm{~m}$ en dirección norte-sur (véase Ciudad et al., en este volumen: fig. 2).

Los rellenos realizados para alojar el asentamiento monumental raramente superan $1,80 \mathrm{~m}$ de profundidad, lo que concuerda con la ocupación estimada de apenas dos siglos. Sobre el seno de roca caliza se distribuye de manera bastante uniforme un lecho de barro negro compacto, culturalmente estéril, que oscila entre 0,30 y $0,40 \mathrm{~m}$ de espesor, y que se interpreta originado por las sucesivas crecidas del río. Los pisos generales del sitio, compuestos de pequeñas piedras calizas compactadas con cal y alisados 
por su parte superior y estucados, cubren primero este estrato de barro negro, luego una capa de piedras calizas informes de tamaño mediano a grande, $\mathrm{y}$, allá donde lo hemos localizado, un tercer estrato de piedras calizas más pequeñas y tierra que apenas supera los $0,35 \mathrm{~cm}$ de espesor.

Estos sucesivos estratos no han documentado ocupación preclásica o de Clásico Temprano de relevancia; algunos fragmentos de cerámica, muy escasos, que identifican estas etapas, quedan relegados al relleno de algunas grandes plataformas y nivelaciones; conclusión que documenta la adscripción de la arquitectura de Machaquilá al Clásico Tardío y al Clásico Terminal. Ha de señalarse, como ya se ha mencionado en la presentación de las operaciones arqueológicas realizadas en la ciudad (Ciudad et al., en este volumen), que la excavación no se diseñó para detectar subestructuras; no obstante, las intervenciones efectuadas en las plazas se consideran suficientes para marcar el inicio de su ocupación en el Clásico Tardío.

El sitio se organiza en torno a ocho plazas de forma básicamente rectangular, aunque algunas -Plazas F y H-adquieren una fisonomía casi cuadrada. Los límites norte y este de la ciudad son muy compactos y cerrados, de modo tal que por el lado más septentrional el único acceso desde el río es una pequeña escalinata que salva el desnivel entre éste y el sitio, y por el noreste y este las estructuras literalmente se apoyan en las laderas del cerro que limita la ciudad. El término meridional y suroccidental es más abierto, aunque se fue cerrando por diferentes construcciones a la conclusión del Clásico Tardío (Ciudad, Adánez e Iglesias 2006; véase infra). Si bien la función de las plazas analizadas es compleja de determinar, podemos entender que la Plaza A era un espacio ceremonial ligado a rituales dinásticos y, aunque esto está sin confirmar, funerarios: es un ámbito constituido por estructuras de tipo templo en el que se concentran por grupos el mayor número de las estelas y los altares tallados de la ciudad. El resto de los espacios parecen tener una naturaleza más residencial elitista y administrativa: la Plaza C tiene dos grandes edificios palaciegos (E-26 y E-29) y un cuadrángulo de estructuras de tipo palacio perecederas, levantándose en su esquina oriental dos estructuras piramidales, de las cuales una (E-24) sostuvo un pequeño oratorio, mientras que la otra (E-44) tenía en su cima una tosca tumba; en el centro de la plaza se halló, quizás recolocada, la Estela 19, tallada. También las Plazas E, G y H muestran una naturaleza residencial; la última mantiene un emplazamiento periférico y no presenta edificios abovedados, mientras que la Plaza G sí resultó un entorno de palacios abovedados en el caso de E-29, E-32 y E-7/8, algunos de los cuales fueron cubiertos o separados de este espacio en el Clásico Terminal. Asimismo, la plaza dispuso de un pequeño oratorio colocado sobre un basamento piramidal al sureste (E27). Por último, la Plaza F es un espacio residencial dedicado, al menos en el Clásico Terminal, a la realeza, de difícil acceso y alejado de la circulación ciudadana.

Esta organización de la ciudad difiere de la que muestran tanto sus vecinas más inmediatas como las situadas a una distancia media, fundamentalmente por la ausencia de una serie de conjuntos arquitectónicos característicos y, en parte en relación con ésta, por su carácter compacto y nucleado -bien adaptado, asimismo, a necesidades defensivas-. Una primera ausencia es la de un conjunto de tipo Grupo E como eje del ritual público, la cual ha de vincularse con la fundación tardía de la ciudad (Laporte, Chocón et al. s.f.). Las exploraciones y excavaciones realizadas en Pueblito y El Chal, 
dos centros activos durante el Clásico Terminal al noreste de Machaquilá, han mostrado que sus conjuntos de este tipo -que inicialmente se consideraron inexistentes (Laporte, Morales y Valdizón 1997) y terminaron por identificarse con el avance de los trabajos de reconocimiento- fueron construidos en el Preclásico y perdieron su carácter de foco ritual y administrativo, cayendo incluso en desuso, a lo largo del Clásico Tardío (Chocón y Laporte 2004: 36; Quezada et al. 1998: 12); al noroeste, la propia Ceibal parece haber contado con un grupo de tipo E -cuya identificación segura ha de esperar al desarrollo de los actuales planes de excavación-asociado a fases preclásicas y a la fundación de la ciudad (Inomata, Triadan y Román 2010). La ausencia de calzadas que unieran grupos monumentales entre sí, en segundo lugar, expresa la inexistencia de más de un núcleo en la conformación del área central de Machaquilá; las dos únicas calzadas registradas conectan uno de los límites de la ciudad con dos grupos perimetrales (Grupos 20 y 21). Más llamativa, y aún sin explicación, es la carencia de un juego de pelota y, asimismo, la falta de acrópolis formal, rasgos ambos que tienen una presencia invariable -e incluso creciente- durante el Clásico Tardío y Terminal en la región del Sureste de Petén. Globalmente, todas estas peculiaridades de Machaquilá pueden relacionarse con una fundación y un desarrollo ligados a un proceso político unitario, diferente al proceso de fisión y segmentación que caracteriza a las ciudades mayas de amplias zonas de Petén (Laporte, Chocón et al. s.f.).

\section{Materiales y técnicas de construcción}

Los arquitectos mayas utilizaron los materiales disponibles en su entorno para levantar sus edificios: palma para techar las construcciones, madera para la misma función y para ser colocada en dinteles, tirantes y demás, y piedra caliza para cimientos, muros, paramentos y techumbres, constituyen el registro de materiales utilizados en la construcción de Machaquilá. La exploración ha puesto de manifiesto un afloramiento de caliza con bloques verticales cortados en la colina en que se asienta la porción oriental del sitio que limita con la Plaza B, lo que permite suponer que los arquitectos se aprovisionaron de los materiales necesarios para construir la ciudad en esta colina y quizás en otras cercanas. Por otra parte, hemos detectado diferentes tipos de composición de la piedra en lo que se refiere a su textura y a su dureza, aunque no se ha podido determinar un patrón de ubicación de las piedras más duras y las más blandas.

La mampostería empleada en Machaquilá a lo largo del Clásico Tardío (Estructuras $20,22,29,31,36$ y 44) deja en el interior de las paredes de los edificios bloques amorfos de mortero compactado de piedras calizas pequeñas y medianas con arcilla arenosa, de color marrón oscuro a rojizo, y cal. Estos bloques están forrados a ambos lados por otras tantas hileras de piedras bien cortadas de factura rectangular a cuadrada, por lo general más grandes en las partes inferiores de los paramentos (hasta 0,50 por $0,25 \mathrm{~m}$ en las zonas bajas de las paredes y 0,10 por $0,20 \mathrm{~m}$ en las altas), $\mathrm{y}$ unidas a soga (Figura 1), de manera que apenas si necesitan cuñas de estabilización. Algunos de los sillares tienen las esquinas ligeramente redondeadas y alcanzan una fábrica casi oblonga. Una parte de los edificios muestra escasos signos de haber estado 


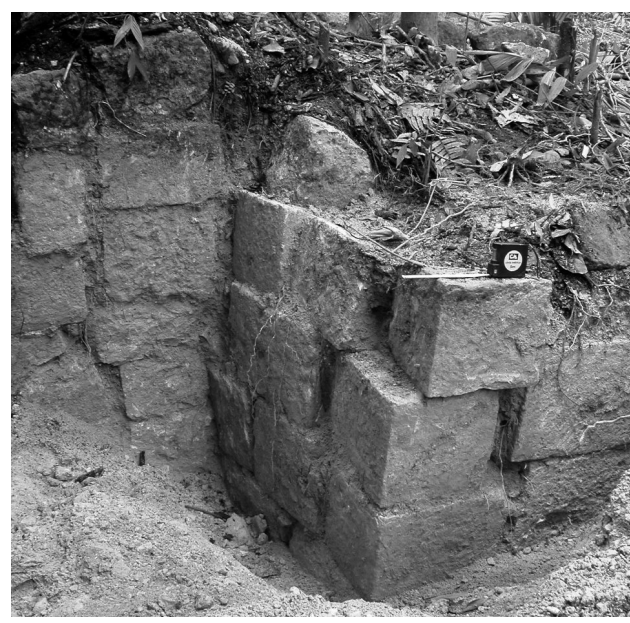

Figura 1: Muro de la Estructura 29-sub.

Figura 2: Escalinatas de la Estructura 34, sobre la Plaza D.

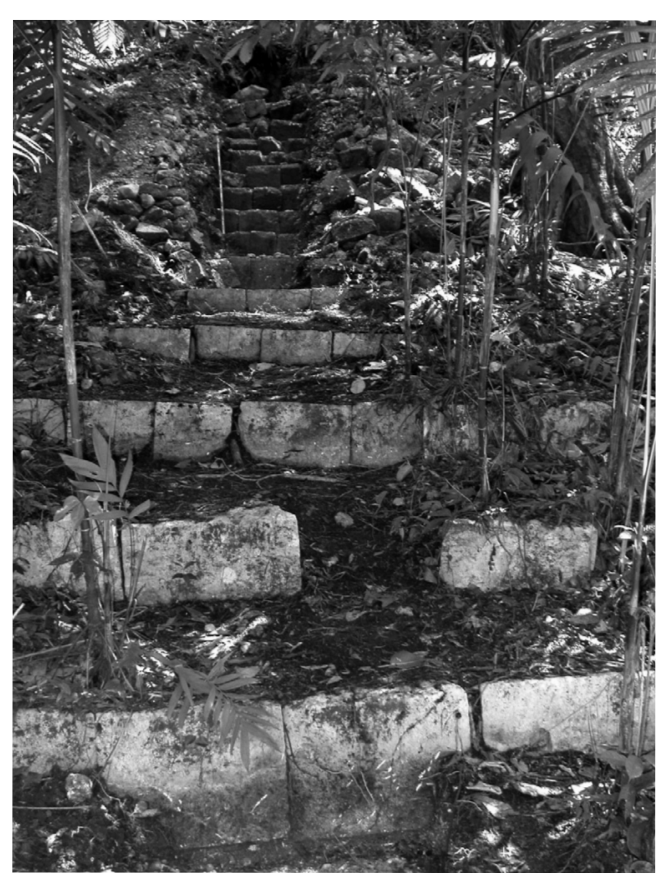

recubiertos con estuco. Se trata de una técnica constructiva tradicional en las Tierras Bajas mayas, al menos en el curso de todo el periodo Clásico.

Las escalinatas están formadas por grandes bloques en forma de paralelepípedo en los tramos inferiores, que van descendiendo en volumen y tamaño según se asciende; bloques que han sido bien cortados y alisados en su cara delantera (Figura 2). El espacio existente entre cada escalón estuvo rellenado con piedras y arena y sellado por una capa de piedrín, la cual fue posteriormente regularizada y estucada. Todas las escalinatas analizadas -supuestamente construidas en el Clásico Terminal a excepción de aquéllas correspondientes a los edificios E-31 y E-32- eran exentas con respecto a los edificios. Las estructuras -sean piramidales con carácter de templo, adoratorios o edificios de tipo palacio- sólo disponen de una escalinata colocada a un lado del edificio, y son de un solo tramo. Algunas de ellas estaban decoradas: la escalinata de E-32 con una alfarda a cada lado (Figura 3) y esta misma, junto con las que proporcionaban el acceso a E-26, E-34 y E-36, tenían decoración de grandes cubos arquitectónicos colocados en el entronque de la escalinata con los muros del basamento que sostuvo los edificios. Estos cubos, dobles en E-36, estaban también exentos, y se habían formado a base de tierra y piedras y forrado mediante bloques de piedra caliza de la misma fábrica que los colocados en los cuartos de los edificios. La decoración de las escalinatas por medio de estos cubos de piedra puede comprobarse en Pueblito, donde se asocian con construcciones elitistas levantadas sobre elevados basamentos a lo largo del Clásico Terminal; por ejemplo, la escalinata de acceso al basamento en que se instala la Acrópolis Central, así como también algunas de las estructuras que conforman dicha Acrópolis (Chocón y Laporte 2007: figs. 12-14). También ha sido 

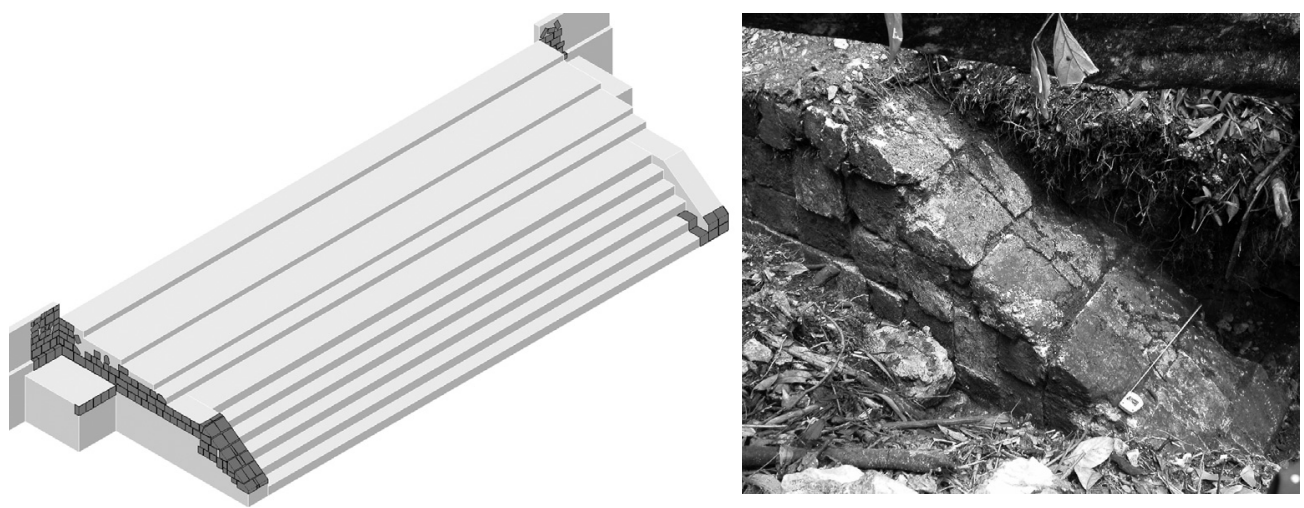

Figura 3: Escalinata de acceso a la Estructura 32 desde el Grupo G-1

(izquierda: reconstrucción isométrica desde el sureste; derecha: detalle de la alfarda sur).

registrada su presencia en El Chal, donde Chocón (2008: 403) lo ha datado para finales de Clásico Tardío. En cualquier caso es un rasgo poco común en el Sureste de Petén.

Las estructuras 7/8, 20,22, 29, 32, 34, 36, 45 y 47 estaban abovedadas, de lo cual es evidencia directa la presencia, entre los derrumbes, de las piedras que, dispuestas en hiladas, formaban las bóvedas. Se trata de bloques alargados, con la cara frontal biselada y unas dimensiones que disminuyen longitudinalmente hasta alcanzar el extremo posterior (Figura 4), mientras que las claves mantenían forma de losa.

Algunos edificios (E-22, E-27 y E-36) estuvieron decorados por simples molduras rectangulares colocadas en la parte baja y media de los basamentos. En el caso de E$7 / 8$, se coloraron sendas molduras en la parte inferior del paramento externo para alojar entre ellas un sofisticado diseño escultórico en mosaico (véase infra). Pero sin
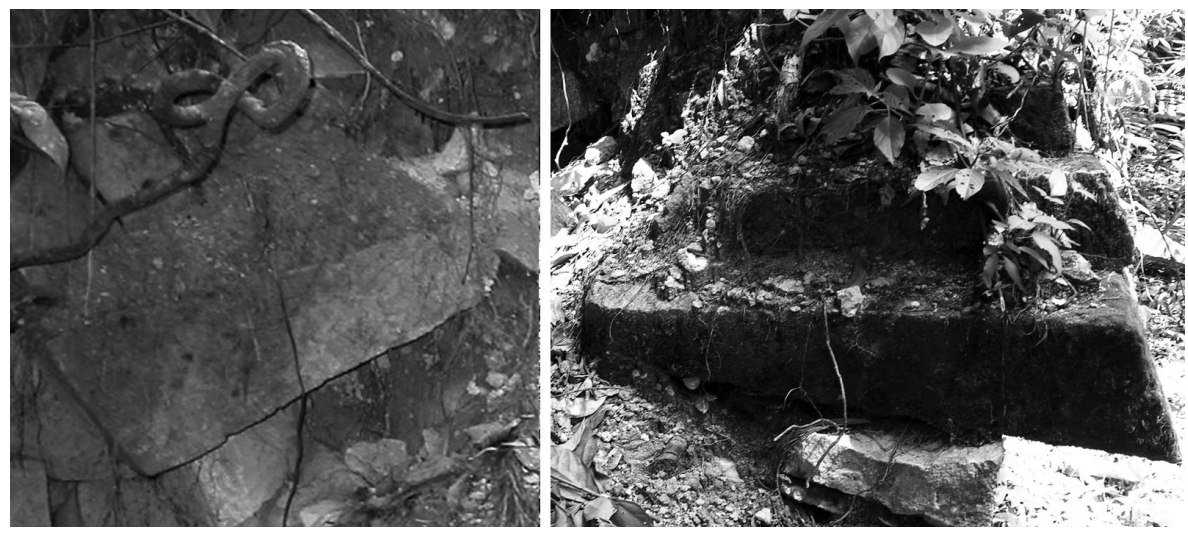

Figura 4: Piedras de bóveda de la Estructura 32

(izquierda: intradós; derecha: trasdós y cornisa exterior). 


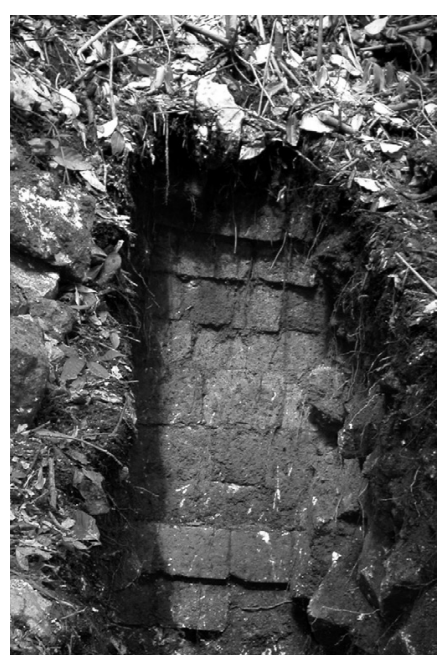

Figura 5: Molduras en el muro de la Estructura 27.

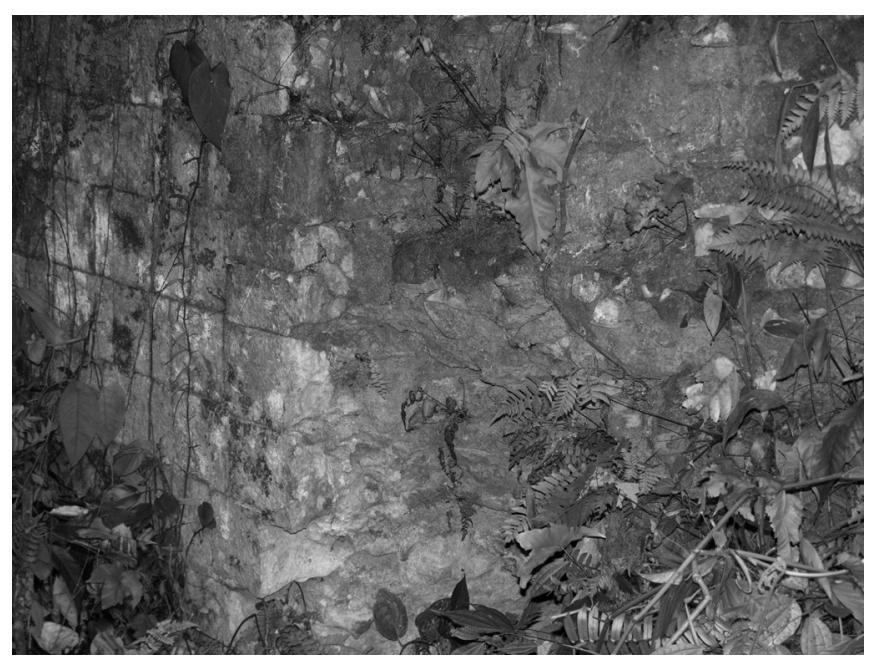

Figura 6: Detalle del muro oeste de la Estructura 32 (obsérvese cómo el núcleo de mortero y piedras irregulares sigue en pie allí donde han caído los sillares que lo revestían).

duda la moldura más compleja se colocó en E-27 (Figura 5); ésta fue doble y concluyó en bisel, de manera que separaba con claridad el paramento del arranque de bóveda y la techumbre, proporcionando al edificio una gran horizontalidad y esbeltez.

El Clásico Terminal introdujo en la ciudad severos cambios, tanto en planificación urbana como en lo que se refiere a las técnicas constructivas y a la decoración (Ciudad y Lacadena 2008). Los únicos edificios abovedados que pueden datarse en este periodo son E-7/8 y E-32, todos los cuales manifiestan continuidad constructiva con las construcciones abovedadas de Clásico Tardío, E-29 y E-36.

La innovación técnica más relevante tiene que ver con la introducción de la mampostería de revestimiento (o piedra de fachada, veneer masonry). Los sillares en forma de paralelepípedo, unidos a soga y con ocasionales y pequeñas cuñas de estabilización, empleados a lo largo de centurias en las Tierras Bajas para formar el exterior de los muros y paramentos, son desplazados en el Clásico Terminal por sillares muy bien cortados y pulidos que se estrechan en su cara posterior para fijarse a un núcleo de mortero y piedras irregulares (Figura 6). La función de estos sillares es menos estructural que la de aquéllos utilizados a lo largo del Clásico, limitándose a cubrir las fachadas de los edificios más que a sustentarlos: una fábrica que permite aligerar la carga de los muros, a la vez que los espacios interiores ganan en amplitud. Esta técnica tiene una amplia distribución en el centro y norte de las Tierras Bajas mayas durante el Clásico Terminal (Pollock 1980). En el Sureste de Petén se ha atestiguado en El Chal, Ixkún, Calzada Mopán, Ixtontón, Pueblito y Ucanal, asociada a edificios de Clásico Terminal, aunque ya existía en algunos casos anteriores, como en el Juego de Pelota de Ixkún (Laporte y Mejía 2002: 67; Valdizón 1995: fig. 9). También está representada en construcciones de esta etapa en Ceibal (Smith 1982: 23). En Machaquilá se ha documentado en el Cuadrángulo (E-38 a E-41) en la Plaza C, en las superestructuras de E-29 y E-36 en las Plazas C y G, en E-32 en la Plaza E, en E-4 en la 


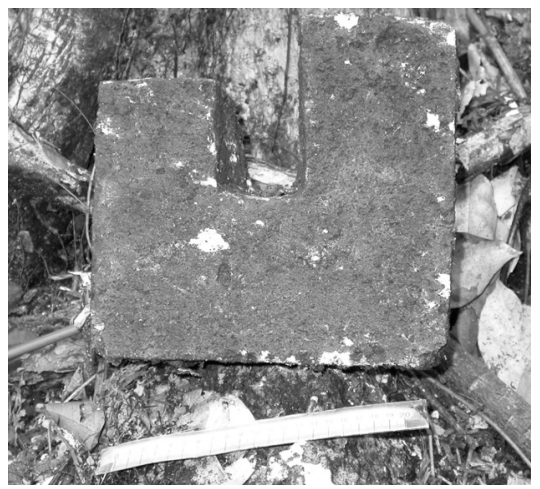

Figura 7: Sillares en forma de U (izquierda: sillar hallado en un derrumbe; derecha: sillar hallado in situ, en un paramento del cuarto delantero central de la Estructura 32, junto con la espiga que tenía introducida).

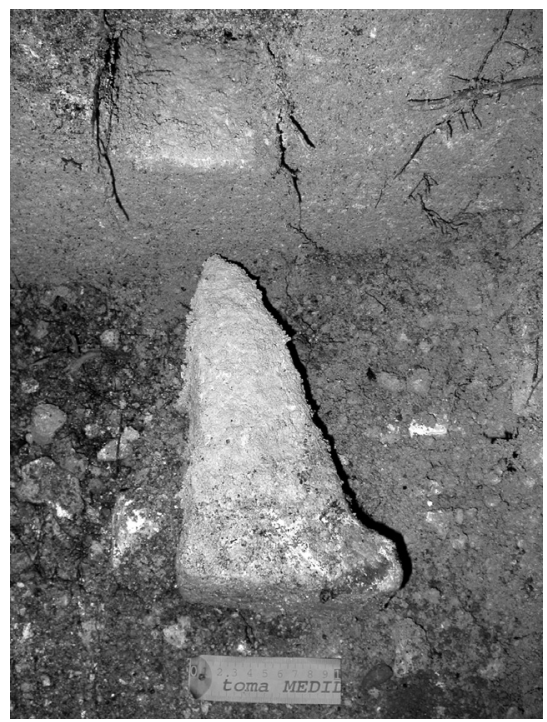

Plaza F, en E-26 en la Plaza G, y en las piedras que conforman el recinto cuadrilobulado de la Plaza A, si bien en este último caso no se trata de verdaderos muros. Es interesante señalar que todos los sitios citados estaban evolucionando políticamente hacia una concepción más centralizada del territorio en estos momentos de Clásico Terminal en que integran esta técnica constructiva, más acorde con modas de mayor distribución en el centro y norte de la península de Yucatán. Con la aplicación de estas piedras de fachada se introducía en estas capitales que sobreviven al Clásico Tardío en el área una técnica muy diferente a la construcción de soga característica de todas las ciudades de Petén desde siglos atrás (Laporte, Mejía y Chocón 2005: 408).

Por último, en edificios y contextos que caracterizan los momentos finales de la ciudad se han encontrado sillares en forma de U preparados para alojar espigas (Figura 7a) -uno de los cuales se encontró in situ, formando parte de uno de los muros interiores de la Estructura 32 (Figura 7b)-, así como lajas que constituían el núcleo de estucos modelados para la decoración de edificios, que se manifiestan en diferentes sitios de Tierras Bajas con dataciones muy tardías del periodo Clásico, como Pueblito (Laporte, Morales y Valdizón 1997), Ceibal (Smith 1982: fig. 43) y Cancuén (Demarest y Barrientos [eds.] 2001, 2002, 2003, 2004, 2005).

\section{Tipos de construcciones}

Como ya se ha señalado, en el registro de Machaquilá resulta destacable la ausencia de algunos tipos y conjuntos arquitectónicos que tienen una amplia distribución en las ciudades de las Tierras Bajas mayas, y de manera más concreta en el Sureste de Petén: ni la exploración de Graham (1967), ni los trabajos llevados a cabo por el Atlas Arqueológico de Guatemala (Laporte [ed.] 2001; Chocón y Laporte 2002), ni los que ha realizado el equipo de la Universidad Complutense, han detectado la existencia de 
juegos de pelota o baños de vapor, o de conjuntos tipo Acrópolis y Grupos E, éstos últimos tan frecuentes en la región y de tan decisiva importancia normativa en la fundación y organización de las ciudades mayas.

En Machaquilá se han hallado 9 estructuras con basamentos piramidales que sostuvieron en su cima edificios. Todas ellas tienen planta cuadrangular y una escalinata. E-24 y E-27 -en la Plaza C y la G respectivamente- tan sólo debieron estar coronadas por reducidos recintos perecederos, quizás santuarios; E-16, E-17 y E-19 no manifiestan edificios de mampostería en su cima y tienen asociados tres, cuatro y cinco estelas respectivamente, así como un altar cada una; E-18 parece ser tan sólo una plataforma, con muy escasa visibilidad; E-20, E-22 y E-44 tuvieron carácter de templo y mantuvieron edificios de mampostería y abovedados en su cima. Como caso distinto debemos considerar a E-34, también una construcción de carácter piramidal -con un basamento escalonado formado por cuatro cuerpos- pero coronada por un edificio alargado de tipo palacio.

Los edificios de tipo palacio son frecuentes en la ciudad; de hecho, se han detectado en todas las plazas analizadas, a excepción de la Plaza A. Éstos presentan una amplia variedad de disposiciones y formas. Desde el punto de vista de los materiales de construcción y del gasto energético empleado en su construcción, pueden distinguirse dos clases. La primera está constituida por los edificios levantados con materiales perecederos y que se asientan sobre una o varias banquetas, presentando sólo una o dos hileras de piedras bien cortadas en su base (E-4, E-14, E-15, E-23, E-25, E-26, E-30, E-31, E-37, E-38 a E-41 y E-45; incluso se incluyen en esta categoría las superposiciones de Clásico Terminal de E-29 y E-36). Algunos de ellos se colocaron sobre banquetas de un solo tramo, otros sobre una doble banqueta e, incluso, sobre una triple, E-14 y E-15 se emparejaron dentro del mismo basamento. Este tipo arquitectónico es particularmente frecuente en la ciudad en tiempos de Clásico Terminal.

La segunda clase viene dada por la existencia de palacios abovedados, que requirieron de superior gasto energético, tanto en la construcción de amplios paramentos para la sujeción de la bóveda como para la aproximación de las pesadas hileras de piedra que cubrieron el edificio. Las versiones de Clásico Tardío de E-29 y E-36, y la transición a Clásico Terminal de E-7/8, E-32 y E-34 (Figura 8) definen esta categoría. No hemos podido determinar la forma definitiva de todos los palacios abovedados detectados en la ciudad, en especial la versión temprana de E-36, que se encuentra muy deteriorada por el saqueo y bastante oculta por su conversión en basamento de una estructura perecedera durante el Clásico Terminal. La versión inicial de E-29 consiste de una doble crujía con tres vanos a la Plaza C y otros tantos a la Plaza G; salvo un acceso interior, desconocemos los vanos internos del edificio que comunican ambas crujías, tanto por la superposición y el saqueo como por estar colmatadas aún varias de sus habitaciones. Por su parte, E-32 es una construcción de doble crujía con tres entradas que miran hacia el este, al Grupo G-1, y un acceso interno en el muro que divide ambas crujías; dos cuartos situados en los extremos norte y sur del palacio, con un solo vano, limitan transversalmente ambas crujías y configuran una planta de tipo «tándem/transversal», la más compleja en la tipología de palacios de Harrison (2003: 103). Las Estructuras 7 y 8 constituyen, en realidad, un mismo edificio con una sola crujía y tres vanos de acceso orientados a la Plaza $\mathrm{G}$ y uno adicional en el lado opuesto, 


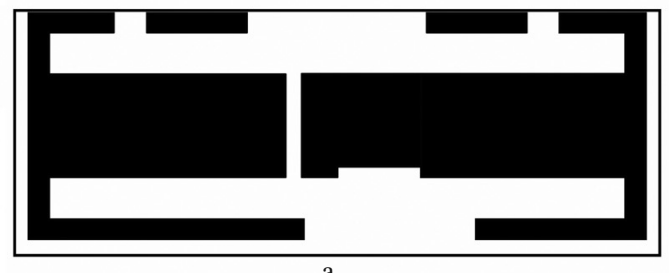

a

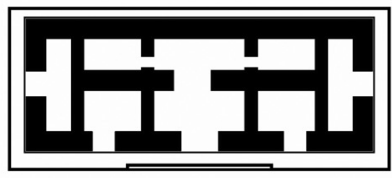

c

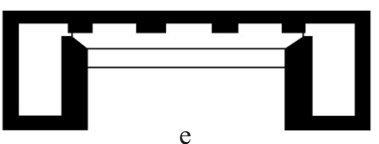

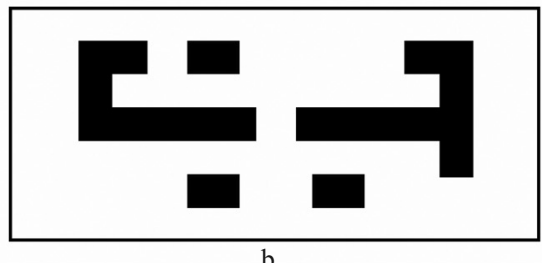

b
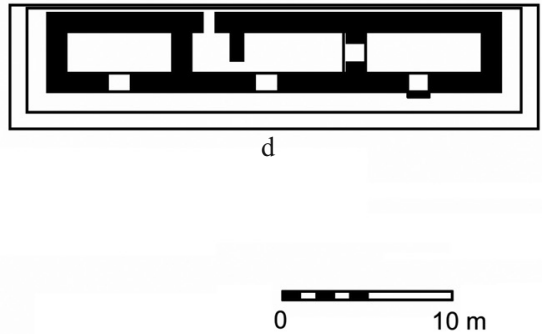

Figura 8: Planta de las estructuras 34 (a), 29-sub (b), 32 (c), 7/8 (d) y 4 (e).

hacia la Plaza F. La Estructura 34, en fin, es el edificio de mayores dimensiones entre los excavados en la ciudad; presenta dos crujías, con tres entradas en el caso de la septentrional y aparentemente con una de gran anchura y descentrada en el caso de la meridional, las cuales están separadas por un muro y un relleno de excepcional grosor, quizá para conformar una plataforma superior o bien para soportar el peso de algún tipo de crestería sobre el edificio.

A los palacios recién mencionados, cuya planta muestra un contorno rectangular, hay que añadir el caso de la Estructura 4, un edificio en forma de $C$, la cual es representativa de los tipos constructivos del Clásico Terminal (Figura 8e). Idéntica planta se encontró en las Estructuras 2 y 3 del Grupo Habitacional 10, ubicado en la periferia sur de Machaquilá, pero también en Pueblito, en sus Grupos 6 y 7, donde han sido fechados asimismo para el Clásico Terminal (Chocón y Laporte 2007). Únicamente en esta Estructura 4 se han encontrado los restos de una posible banca, cuya existencia se infiere a partir de la ordenación de una colección de bloques de distintas formas y dimensiones con textos glíficos en sus caras (Lacadena, en este volumen: fig. 13; Iglesias y Lacadena 2003; Lacadena e Iglesias 2005). No obstante, el tipo de operaciones de excavación realizadas no puede descartar la existencia de bancas en el interior de alguno de los edificios de tipo palacio.

Las Estructuras E-38 a E-41 conforman en conjunto -al disponerse sobre una plataforma basal y componer en su superficie un grupo cerrado en torno a un patio central- un tipo arquitectónico individualizable, conocido en las Tierras Bajas mayas como cuadrángulo. Elevado con técnicas constructivas propias del Clásico Terminal, se trata de un tipo frecuente en el norte de las Tierras Bajas (Pollock 1980), pero escaso en el sur. En el Sureste de Petén, no obstante, se ha encontrado un cuadrángulo arquitectónico en la parte posterior de la Plaza C de Pueblito, al cual se le adscribió una función residencial elitista o administrativa (Valenzuela 2006: 258), y también ha sido 
registrado en El Chal (Morales 1995; Morales y Laporte 1995); asimismo, se ha documentado en el Grupo A-19 de Naranjo (Aquino 2005).

Un tipo arquitectónico singular es el Cuadrilobulado emplazado en la Plaza A: un recinto de $8 \mathrm{~m}$ de lado, rebajado $0,20 \mathrm{~m}$ en relación con el piso de la Plaza A y delimitado por una hilera de piedras bien canteadas en su cara expuesta. Su ubicación y forma, así como los restos óseos y de cultura material recuperados en él, junto con la documentación epigráfica e iconográfica obtenida, sugieren que se trata de un espacio de naturaleza ritual que alcanzó gran relevancia en los momentos finales del Clásico Tardío y en el Clásico Terminal de la ciudad. En él parecen haberse realizado ceremonias vinculadas con rituales de fuego y con seres relacionados con el agua, y, en ocasiones, a ritos calendáricos (Lacadena 2006; Ciudad, Lacadena et al. 2010; Lacadena, en este volumen). La presencia de este tipo de construcciones asociadas al centro de las plazas más importantes de las ciudades mayas es muy escasa; sólo se han registrado estructuras cuya forma puede considerarse similar -aunque no idéntica ni necesariamente ligada al mismo tipo de ritos- en La Blanca (Retalhuleu), presumiblemente del Preclásico Medio (Love et al. 2006), Cival, del Preclásico Tardío (Bauer et al. 2005), y Cancuén, de finales del Clásico Tardío (Barrientos, Demarest et al. 2006).

\section{Decoración}

La decoración arquitectónica detectada en Machaquilá se desarrolla en dos formatos principales, ambos determinantes del periodo Clásico Terminal. Laporte y Mejía (2002: 67-68) señalan que uno de los rasgos que definen el paso del Clásico Tardío al Clásico Terminal en el Sureste de Petén, y sobre todo en la cuenca del río Mopán, es la aparición de un nuevo estilo de decoración arquitectónica a base de mosaico de piedra mediante el ensamblaje de pequeños bloques tallados en bajo relieve para representar rostros de individuos y su ornamentación por medio de tocados, orejeras y demás elementos. En Machaquilá se han encontrado restos de este tipo de decoración en las estructuras 20, 27 y 44, aunque está representada por fragmentos tan pequeños que no es posible reconstruir los diseños a que corresponde. Disponemos de piezas pertenecientes a rostros o partes del cuerpo de seres humanos -quizás mascarones- $\mathrm{y}$ a la decoración de sus vestimentas y símbolos. Si bien se trata de una técnica poco usual en las Tierras Bajas Centrales, este tipo de decoración se ha detectado, de manera más abundante y determinante, en Ixtontón, Calzada Mopán y Pueblito (Laporte, Morales y Valdizón 1997). Laporte (s.f.) estima que podría representar un estilo regional para los mascarones de Clásico Terminal.

Esta misma técnica ornamental se utilizó para decorar las fachadas meridionales de la Estructura E-7/8 (Figura 9): el programa decorativo aplicado en la fachada sur de esta construcción recrea la Montaña de las Flores, un próspero lugar donde se protagonizó una actualización permanente del mito del origen del alimento de los seres humanos (Lacadena e Iglesias 2006). Los distintos elementos que integran la representación escultórica - dos columnas de sendos mascarones flaqueando un vano de entrada concebido como las fauces abiertas de una cueva cuyas mandíbulas están de- 


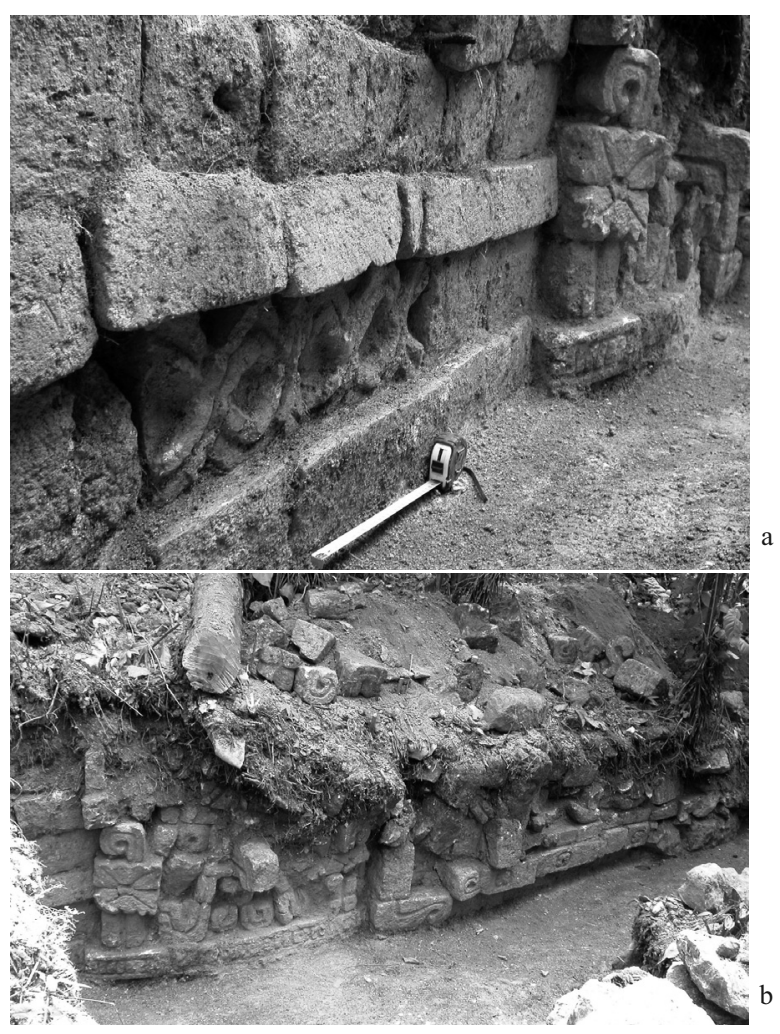

Figura 9: Decoración en mosaico de la fachada de la Estructura 7/8: (a) moldura e inicio de mascarón; (b) mascarón; (c) motivo en greca; (d) motivo entrecruzado; (e) motivo en voluta; (f) columnillas.
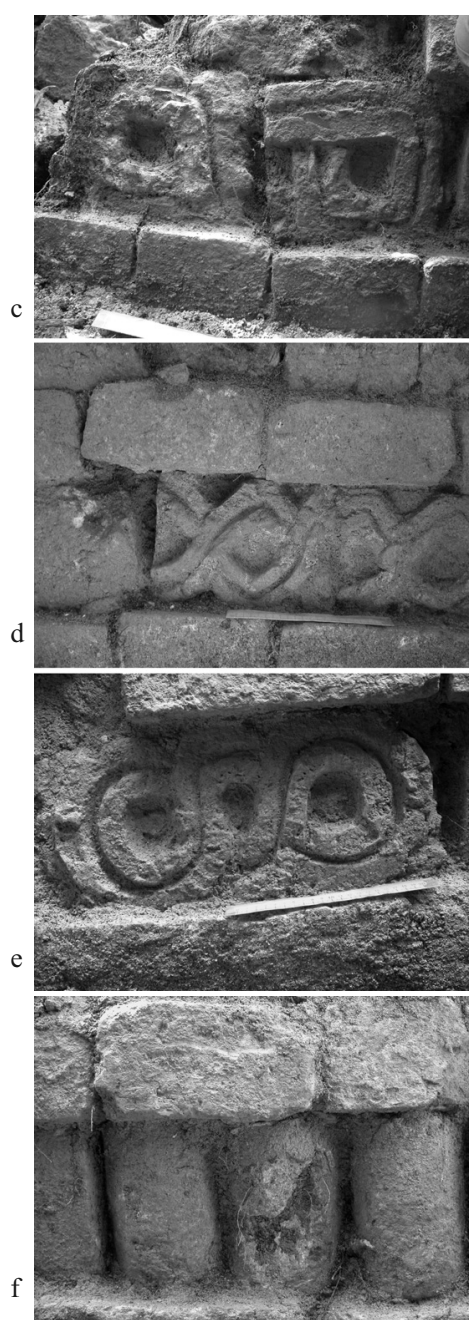

coradas con flores- se encuentran tallados en sillares independientes ensamblados con la técnica de mosaico. Otro elemento vinculado a esta técnica de decoración característica del Clásico Terminal en la ciudad, y presente asimismo en E-7/8, es la utilización de columnillas ciegas, en grupos de tres, para decorar los zócalos de los edificios. Resulta sumamente interesante que las columnillas ciegas sean un rasgo recurrente también en la decoración externa de los edificios del centro y norte de Yucatán desde el periodo Clásico Tardío y a lo largo del Clásico Terminal (Pollock 1980).

Junto a la decoración escultórica en mosaico, bien distribuida por la ciudad en edificios del Clásico Terminal, también fue importante la escultura arquitectónica en estuco, en este caso limitada a la Estructura 34, en las Plazas D y E (Figura 10). Sobre el piso superior de la Plaza E, junto al basamento de la mencionada estructura, aparecieron grandes acumulaciones de estucos modelados y fragmentados en piezas de diversos tamaños, los cuales debieron caer de la parte superior del edificio. Tales estucos 

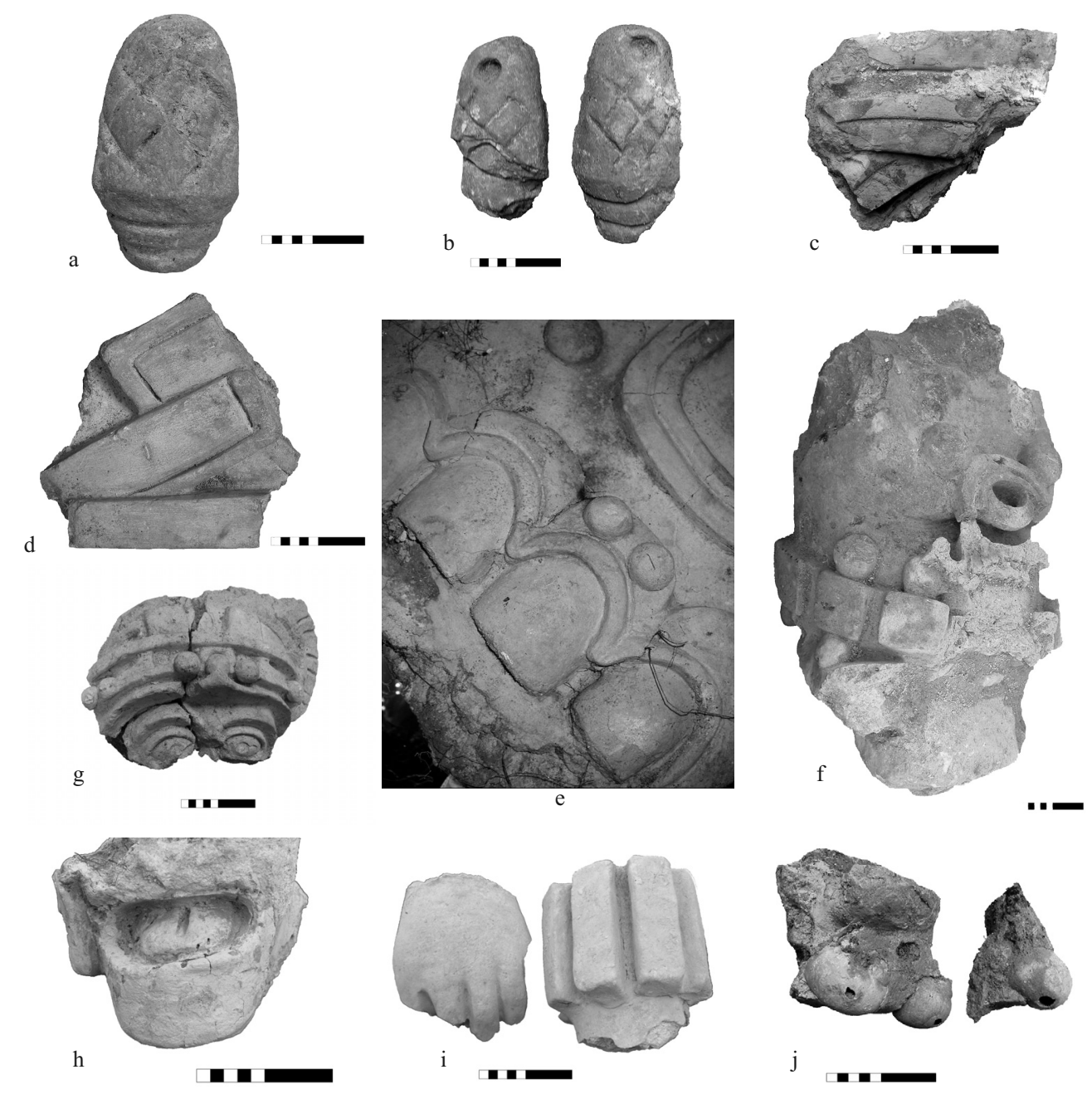

Figura 10: Algunos fragmentos de estuco modelado procedentes de la Estructura 34: (a) y (b) representación de mazorcas; (c) representación de plumería con restos de pintura; (d) símbolo de estera o pop; (e) mascarón; (f) torso; (g) parte superior de la cabeza de un personaje; (h) boca y barbilla de un personaje; (i) mano y muñequera; (j) conchas de caracol insertas en el estuco.

estuvieron montados en ocasiones en torno a una estrecha laja de piedra caliza necesaria para dar consistencia a las figuras representadas; una solución compartida en Cancuén y Ceibal, y muy similar a la empleada en los estucos de Palenque. Los motivos que componen incluyen figuras humanas y, quizás, divinas, ricamente ataviadas y con símbolos de alto estatus; también se han rescatado otros fragmentos que incluyen conchas completas de caracoles de agua dulce, que quizá fueran elementos integrantes de los propios motivos. 
La evidencia encontrada en diferentes centros del entorno geopolítico de Machaquilá indica que esta decoración en estuco, ubicada en frisos y molduras superiores de edificios, incluye figuras con elementos antropomorfos -en Machaquilá es el caso de un mascarón que muestra decoración de pintura en varios tonos (Figura 10e)-, acompañadas de figuras a escala natural -como un torso (Figura 10f) - ricamente ataviadas, y de diseños florales y faunísticos (Ciudad y Lacadena 2008). Aunque no existe una evidencia generalizada en el área para finales de Clásico Tardío e inicios del Clásico Terminal, su disposición, composición y diseño es indicativo de las transformaciones que sufre la región a finales del siglo VIII. De modo que tan sólo se ha documentado en centros de naturaleza regional que mantuvieron su importancia en el Clásico Terminal: es el caso de Pueblito, donde Laporte, Morales y Valdizón (1997) han registrado la existencia de un torso similar al encontrado en Machaquilá, junto con otras piezas de menor entidad, pero igualmente de un formato común.

La mayor cantidad de escultura arquitectónica en estuco se ha encontrado en el Palacio Norte de la Acrópolis Central de Pueblito, un edificio de tipo palacio de cinco cámaras abovedadas. En el escombro se encontraron piedras talladas con motivos geométricos y figurativos, que corresponden a un peculiar estilo decorativo alojado en los frisos de los edificios. En ellos se emplazó un armazón de piedra caliza y la figura modelada mediante una gruesa capa de estuco. Los diseños detectados incluyen volutas decoradas con puntos aplicados y molduras, así como figuras zoomorfas, antropomorfas y posiblemente jeroglíficas (Chocón y Laporte 2007: 520; figs. 25 a 28). Más importante aún es la rica información obtenida en el palacio L7-9, «Edificio de los Retratos», de Cancuén, donde se han rescatado más de 5.000 fragmentos de estuco correspondientes a diseños que decoraban el friso de este palacio, los cuales incluyen figuras de gobernantes de gran tamaño, ricamente ataviados, y representaciones de flora y fauna local (Barrientos, Larios, Seijas y Luin 2003; Barrientos, Larios y Luin 2003; Demarest y Barrientos 2004).

Quizás, el arquetipo de este nuevo modelo decorativo que se fija en determinadas construcciones -tanto palaciegas como templarias- sea el que quedó plasmado en la Estructura A-3 de Ceibal, cuya posible iconografía fue reconstruida por Tatiana Proskouriakoff (en Smith 1982: figs. 15 y 16). Esta rica decoración cubría todo el friso de la construcción en sus cuatro lados, y combinaba figuras a diferentes escalas para representar gobernantes, deidades y sus adornos, flora, fauna e, incluso, textos jeroglíficos; componía un diseño seguramente de naturaleza similar al encontrado en Machaquilá y Cancuén. Gordon Willey (en Smith 1982: 30-52; Willey y Smith 1967) ha realizado un detallado análisis de este friso de estuco de la Estructura A-3 de Ceibal, el cual sirve para poner de manifiesto la vinculación estilística de estos tres sitios.

Recientemente, también en Ceibal, Erick Ponciano et al. (2007: 452-453, figs. 5 a 8) han excavado el Grupo A-16, donde recogieron una considerable cantidad de fragmentos de estuco modelado sobre el piso. Tales fragmentos - procedentes de la parte superior del muro exterior frontal de un edificio de tipo palacio, abovedado, con múltiples cuartos y una doble crujía- formaron parte de un friso estucado con figuras humanas y otros motivos modelados no reconocidos. Varios de ellos presentaban restos de pintura naranja, amarilla y verde. Al igual que en los sitios anteriormente reseñados, algunos fragmentos de estuco estaban montados sobre piedras talladas que formaron 
parte del paramento, pero de manera muy interesante otros estaban soportados sobre fragmentos de cerámica. Los investigadores del Grupo A-16 de Ceibal apoyan la posibilidad de que este edificio fuera un palacio real del Clásico Terminal.

La datación de esta escultura arquitectónica en estuco aparecida en el sur de Petén corresponde a la última fase del Clásico Tardío y a los inicios del Clásico Terminal: Demarest y Barrientos (2004) la sitúan en Cancuén como una iniciativa del rey Tah Chan Ak hacia 760 d.C., mientras que la Estructura A-3 de Ceibal fue levantada entre el 830 y el 849 d.C. (Smith 1982: 55); por su parte, la Estructura 34 de Machaquilá se puede estimar propia de los momentos postreros de la ocupación elitista de la ciudad, seguramente posterior al 800 d.C., es decir, del Clásico Terminal. Chocón y Laporte (2007: 558) opinan que tal decoración escultórica en armazones de piedra y recubiertos de estuco define un nuevo estilo en que se funden elementos que habían sido desarrollados desde el final del Clásico Tardío en otras ciudades mayas, tanto de Honduras como de Yucatán; un estilo que muestra un alto grado de originalidad y es el resultado de la innovación que permite la prosperidad de algunas ciudades del sur de Petén y de la cuenca del Pasión durante el Clásico Terminal. Tanto Triadan y Palomo (2010) como Demarest et al. (2008), desde las evidencias de Ceibal y Cancuén respectivamente, coinciden en señalar que el estilo tiene su procedencia en Palenque, sobre la base de claras similitudes en las técnicas de elaboración. Demarest y sus colaboradores apuestan por la existencia de una importante red comercial, alentada y controlada por Cancuén, que sorteaba la región del Petexbatún -muy inestable a fines del Clásico Tardío- y se dirigía por el suroeste hacia el río Salinas, para derivar hacia el norte y conectar con el Usumacinta; por el noreste, esta ruta comercial incluiría a Machaquilá -bajo la hegemonía de Cancuén desde su conquista por Tah Chan Ak- y, a partir de ella, conectaría con los centros del sur y este de Petén.

\section{Diseño urbanístico}

Hace ya tiempo que la mayística descartó la vieja idea de que las capitales del Clásico eran exclusivamente centros ceremoniales sin población residente; el área central de Machaquilá cuenta, como se ha visto, con edificios y plazas de carácter residencial, bien que de elite, y en su entorno se dispusieron grupos domésticos. Esta constatación no estorba, sin embargo, el que fueran también escenario de rituales. Algunos autores han defendido la tesis de que la posición social y política de las elites mayas se basaba, antes que en un control de claves económicas, en la revalidación de una ideología que les otorgaba el protagonismo, conformando un «Estado-teatro» en el que la realización de rituales públicos era el elemento crucial (Demarest 1992); no es necesario comprometerse con todos los extremos de esta tesis para advertir, en cualquier caso, la importancia del ceremonial y la ideología en la sociedad maya antigua y, más concretamente, en el diseño de sus ciudades. Parece claro que la planificación de amplias plazas, algunas con estelas y altares, rodeadas de edificios de carácter monumental -que en ciertos casos son soporte de programas iconográficos-y dotadas de calzadas que conducen hacia ellas, responde, entre otros aspectos, a previsiones sobre los rituales que había de albergar la ciudad. Más aún: puesto que las ciudades eran la sede 
de las capas dirigentes y de la propia acción de gobierno, esos rituales necesariamente hubieron de insertarse en la ideología política y, en esa medida, las previsiones urbanísticas en torno a ellos se revelan como una vertiente de dicha ideología y su plasmación arquitectónica como una materialización del modo en que era concebido y presentado el poder de los gobernantes. Ésta es la perspectiva básica que aquí se adopta para explorar las características del diseño urbano que ordenó e integró los tipos de construcciones revisados más arriba.

La estructura de la ciudad puede analizarse, desde el punto de vista señalado, tomando como guía dos cualidades básicas: el tamaño de sus distintas plazas y la posición de éstas en las pautas de circulación dentro de la ciudad (Ciudad, Adánez e Iglesias 2006; véase también Ciudad y Adánez 2006; Ciudad, Lacadena et al. 2010). El tamaño de las plazas se relaciona con las previsiones acerca del número de personas que-siempre pensando en su capacidad para la realización de ceremonias de carácter variablemente público- podían albergar (Inomata 2006). La posición se refiere en este caso a su mayor o menor accesibilidad, medida en términos de profundidad desde el exterior, esto es: el número de ámbitos que un asistente había de atravesar para llegar a cada una de ellas (véase Hillier y Hanson 1984; Moore 1996a y 1996b; Liendo 2003). En combinación, ambas cualidades indican el tipo y volumen de público para el que fueron diseñadas las plazas.

\subsection{La configuración urbana en el Clásico Terminal}

La observación del plano de Machaquilá - que se corresponde, obviamente, con su última fase de pleno funcionamiento, durante el Clásico Terminal- advierte rápidamente que la zona más franca de la ciudad, y en la que se encuentran sus plazas de mayores dimensiones, es la meridional, mientras que la parte norte reduce el tamaño de sus espacios abiertos y los yuxtapone de manera más compacta. Las pautas de circulación desde el exterior están marcadas por ese mismo esquema (Figura 11). Un hipotético transeúnte que visitara el centro urbano con cierta formalidad entraría en él a través de alguna de las dos calzadas del sitio y, atravesando el Grupo 22, accedería a la Plaza D y, sólo desde ella y sucesivamente, a las plazas A y B. En los $11.000 \mathrm{~m}^{2}$ de la Plaza D, nuestro transeúnte podría haberse unido a un numeroso grupo de espectadores de algún tipo de actuación; si suponemos que esos espectadores ocupaban por completo la plaza, sólo la mitad de ellos habría podido asistir a alguna forma de reunión multitudinaria en la Plaza $\mathrm{C}$ y únicamente un sexto habría podido entrar a la Plaza A o a la B. La zona meridional de la ciudad constituye, aun con estas diferencias en su seno, el área pública. La parte norte, sin embargo, impone más limitaciones, tanto al aforo como al acceso, y alberga espacios más privados que, en conjunto, trazan un complejo de carácter palaciego articulado en torno a la Plaza G. En primer lugar, el tránsito hacia ella desde la zona pública no puede producirse sino ascendiendo por escaleras y atravesando plataformas ocupadas por edificios - una vía de acceso con un perfil restringido- para alcanzar la Plaza G, directamente o previo paso por la $\mathrm{H}$, y, desde la primera, el Grupo G-1 y la Plaza E o, de forma aún más restringida, la Plaza F. En segundo lugar, el tamaño relativo de estas plazas disminuye, especialmente 


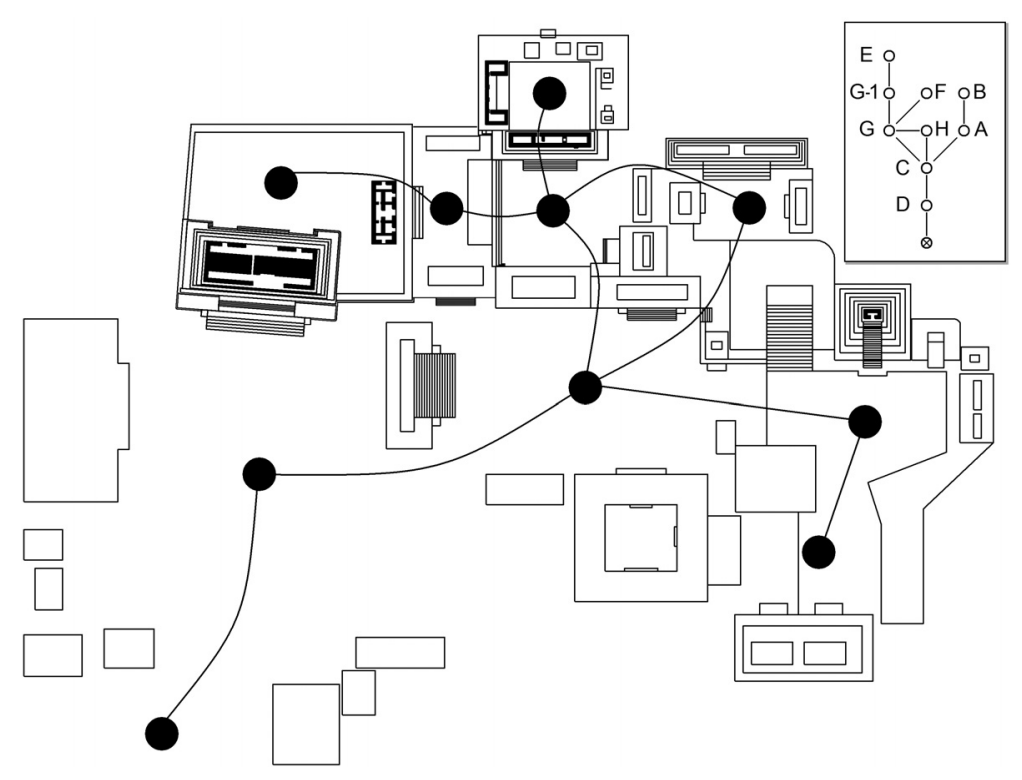

Figura 11: Accesos entre las plazas del área central durante el Clásico Terminal (arriba, a la derecha, se incluye el grafo justificado correspondiente).

en el caso de la Plaza F y el Grupo G-1, si bien con excepciones. Su carácter palaciego lo pone de manifiesto la combinación del tipo de estructuras que alberga y los atributos, escultóricos y epigráficos, con los que se dotó a éstas.

Público y privado constituyen, no obstante, cualidades cambiantes en función del sujeto y de la ocasión. La vinculación entre acciones y lugares -qué es aceptable o aconsejable hacer dónde, cuándo y por parte de quiénes- se regula culturalmente mediante lo que cabe denominar un régimen de exclusividades (véase García 1976) que exige o prefiere, para un tipo de acción y lugar, la presencia de ciertas categorías y cantidades de personas -la «exclusividad positiva»- y exige o prefiere la ausencia de otras - «exclusividad negativa»-. Si la observación general del tamaño y la accesibilidad de las plazas de Machaquilá permite distinguir entre una zona pública y una privada, un análisis más detallado de ambas variables, apoyado también en otro tipo de evidencias, puede detectar algunos elementos del régimen de exclusividades que su diseño asumió y materializó. El Cuadro 1 ordena, para ello, las plazas en función de su grado de profundidad desde el exterior, añadiendo la información sobre su tamaño, sobre el cálculo del número de personas que pudo albergar simultáneamente cada una de ellas y sobre su «asimetría relativa» (Hillier y Hanson 1984: 152-153) o grado de segregación/integración -valores altos o bajos, respectivamente, en el índice- de cada plaza en el conjunto sobre la base de la red de conexiones consideradas. Las cifras que recoge el cuadro muestran la señalada asociación general entre la profundidad desde el exterior y el tamaño de las plazas, poniendo de manifiesto, asimismo, las excepciones a que se ha aludido más arriba, las cuales van a ser útiles para advertir matices interesantes. 
Cuadro 1: Accesibilidad y tamaño de las plazas del área central de Machaquilá (Clásico Terminal)

\begin{tabular}{lccccc}
\hline \multicolumn{1}{c}{ Ámbito } & $\begin{array}{c}\text { Profundidad } \\
\text { de acceso }\end{array}$ & $\begin{array}{c}\text { Tamaño } \\
\left(\mathbf{m}^{\mathbf{2}}\right)\end{array}$ & $\begin{array}{c}\text { Capacidad }^{\mathbf{a}} \\
\text { (personas) }\end{array}$ & $\begin{array}{c}\text { Capacidad }^{\mathbf{b}} \\
\text { (personas) }\end{array}$ & $\begin{array}{c}\text { Asimetría } \\
\text { relativa }\end{array}$ \\
\hline Exterior & 0 & - & - & - & 0,56 \\
Plaza D & 1 & 11.000 & 23.913 & 3.055 & 0,33 \\
Plaza C & 2 & 6.000 & 13.043 & 1.666 & 0,17 \\
Plaza A & 3 & 1.800 & 3.913 & 500 & 0,33 \\
Plaza G & 3 & 1.600 & 3.478 & 444 & 0,19 \\
Plaza H & 3 & 1.100 & 2.391 & 305 & 0,28 \\
Plaza B & 4 & 1.700 & 3.695 & 472 & 0,56 \\
Plaza F & 4 & 900 & 1.956 & 250 & 0,42 \\
Grupo G-1 & 4 & 700 & 1.521 & 194 & 0,36 \\
Plaza E & 5 & 2.200 & 4.782 & 611 & 0,58 \\
\hline
\end{tabular}

${ }^{a}$ Estimación basada en una densidad de $0,46 \mathrm{~m}^{2}$ por persona.

${ }^{\mathrm{b}}$ Estimación basada en una densidad de $3,6 \mathrm{~m}^{2}$ por persona.

En principio, y tomando como guía únicamente los niveles de profundidad, a la distinción entre una zona pública y una privada en el plano de la ciudad puede ahora superponérsele la discriminación de tres tipos de plazas: abiertas, restringidas y altamente restringidas -con niveles de profundidad, respectivamente, de 1 y 2,3 y mayor de 3-. El grupo abierto lo componen las Plazas D y C, las cuales, siendo a la vez las mayores y más accesibles, estarían diseñadas considerando la realización de rituales con una audiencia masiva. Ambas muestran, por las estructuras que incluyen, un carácter residencial-administrativo, destacando sus índices de asimetría el papel distribuidor del tránsito en el centro urbano que tiene la segunda. Lo que llama la atención de este grupo es la ubicación de la Plaza A -tanto por su profundidad como por su tamaño- fuera de él. La Plaza A constituye un espacio con un marcado carácter religioso y seguramente funerario, ligado, como muestra la concentración en ella de 16 estelas asociadas a estructuras de tipo templo y la presencia del Cuadrilobulado, a los rituales dinásticos de los gobernantes de Machaquilá (véase Lacadena, en este volumen). Varios autores han subrayado la importancia de las estelas en los rituales públicos del Clásico maya sobre la base de su presencia en las plazas de mayor capacidad (Sánchez 2005; Inomata 2006); es en este sentido que la Machaquilá del Clásico Terminal resulta anómala. La accesibilidad y el tamaño medios de la Plaza A no excluyen, desde luego, la celebración de ceremonias públicas en su seno, pero sí sugieren para éstas una audiencia más exclusiva en un escenario algo más segregado. Por otro lado, las estelas no están ausentes en el sector público (véase Lacadena, en este volumen: fig. 1). La Plaza D -la mayor- contaba de hecho con tres, dos situadas al pie de la Estructura 34 y una en el extremo sur de la plaza; la Plaza C, por su parte, tiene todavía dos estelas, si bien su ubicación no es con certeza la original, a las que hay que añadir una más hoy desaparecida del sitio. A pesar de estos matices, la desproporción en el número de monumentos y la diferente función de sus edificios apuntan hacia un sector público con énfasis en rituales masivos de una vertiente más real-administrativa que dinástica-funeraria, un fenómeno que quizá no sea tanto una peculiaridad de Machaquilá cuanto un elemento por integrar en la tendencia hacia una organización política más centralizada y unitaria que se ha considerado propia del Clásico Terminal en zonas vecinas del Sureste de Petén (Laporte y Mejía 2002: 81). 
El grupo de acceso restringido está formado por las Plazas A, G y H, con un tamaño claramente menor que el de las anteriores y posible escenario de ceremonias más exclusivas, si bien de carácter muy distinto: dinástico-funerario en el primer caso -como se acaba de indicar- y más residencial en los otros dos. En efecto, las Plazas G y H forman parte de lo que más arriba se ha caracterizado como un complejo palaciego, en cuyo seno operan como receptoras y distribuidoras de la circulación, especialmente la Plaza G. Esta última constituye el corazón mismo del complejo: a ella se orienta la fachada de la Estructura 7/8, decorada con los relieves cuya iconografía se ha relacionado con la recreación del mito de la Montaña de las Flores (Lacadena e Iglesias 2006), pero también uno de los frentes de la Estructura 29 -cuyo edificio original ya habría sido cubierto en este momento para integrar el basamento de uno nuevo, posiblemente construido con materiales perecederos- $y$ la relativamente pequeña Estructura 27, a la que se ha propuesto considerar el adoratorio oriental, dedicado al culto a los antepasados de un linaje, propio del denominado Plano de Plaza 2 (Bazy 2010: 134; véase también, sobre la definición y las implicaciones del Plano de Plaza 2 a partir del caso de Tikal, Becker 1982 y 2003); a ella se orienta también, en fin, el frente del palacio abovedado que constituye la Estructura 32. En este contexto, la extensión relativamente elevada de la plaza ha de vincularse con su grado de monumentalidad y, de ahí, con el grado de distinción social reconocido a sus moradores, pertenecientes a la elite gobernante de Machaquilá. Los esfuerzos iconográficos y arquitectónicos invertidos sugieren la realización en ella de rituales importantes, pero seguramente circunscritos a las elites.

El grupo altamente restringido está formado por las Plazas B, F y E y el Grupo G1 , ámbitos que tienen distinto carácter $\mathrm{y}$, en lo relativo a la asociación entre accesibilidad y tamaño, incluyen las excepciones que suponen las plazas E y B -respectivamente la tercera y la quinta de la ciudad en términos de extensión-. La Plaza F, como grupo residencial de elite ubicado dentro del complejo palaciego, condensa bien las propiedades esperables de este tercer y último tipo. El que una de sus estructuras -la 4- estuviera dedicada a una esposa del ajaw y contara con textos epigráficos posiblemente dispuestos en una banca (Iglesias y Lacadena 2003), junto con el hecho mismo de que forme un grupo completo dentro del complejo, indica la asociación de sus moradores con el estrato social más elevado; es de suponer que las ceremonias que se escenificaran en la Plaza F tendrían, efectivamente, una audiencia muy restringida, en consonancia con su vertiente residencial altamente segregada, pero, dada la elevada posición social de sus residentes, seguramente no carecerían de sentido político. El Grupo G-1, por su parte, parece constituir una antesala de la Estructura 32 y, quizá, un posible escenario visible desde ésta y desde la vecina Plaza G.

En lo relativo a la excepcionalidad de las plazas B y E, hemos de dejar de lado la primera; desafortunadamente, no sabemos lo suficiente sobre ella como para intentar entender su anómala clasificación, dado su tamaño y su ubicación en la zona meridional de la ciudad, dentro del grupo de ámbitos altamente restringidos. La Plaza E, sin embargo, pudo trabajarse con mayor detalle y ofrece un caso interesante: una de sus dos estructuras principales, la 32 , abre su fachada hacia el complejo palaciego, mientras que la otra, la 34, se orienta hacia la extensión de carácter público constituida por la Plaza D; ambas, de hecho, dan la espalda a la propia plaza sobre cuyo basamento 
se localizan -totalmente la Estructura 32 y al menos en parte la 34-. Este vínculo simultáneo y bifronte con la zona residencial de elite y con el lugar más público del centro urbano define el carácter de la plaza y en él cabe inscribir el desajuste entre su tamaño real y el pronosticable en principio a tenor de su nivel de profundidad. No se trataría de un espacio destinado a reunir audiencias multitudinarias; el acceso a él a través de la Plaza G y el Grupo G-1 impone limitaciones claras y el itinerario, en principio posible, que atraviesa la Estructura 34, ascendiendo a ella por su escalinata principal y descendiendo luego por alguna de las tres traseras, es demasiado intrincado y, cabe suponer, reservado. Resulta sugerente pensar en la Plaza E, entonces, como un espacio ritual entre bastidores, segregado en términos de circulación -y también de acceso visual- y, al mismo tiempo, vía de comunicación interna entre el núcleo del complejo palaciego y el escenario público que constituiría el frente de E-34. La decoración escultórica en estuco que adornó a esta última, tanto en su frente como en su parte posterior -los fragmentos de estuco aparecieron especialmente concentrados, no obstante, entre los derrumbes de esta parte posterior, sobre el piso de la Plaza E-, subraya el valor otorgado al edificio y a la propia plaza y nos recuerda, asimismo, que el protagonismo de las elites gobernantes en la interpretación de una serie de papeles rituales ante una audiencia no está reñido con la implicación de esas elites en la ideología que escenificaban.

\subsection{La configuración urbana en el Clásico Tardio}

Los resultados del análisis realizado pueden ganar en profundidad si se observan sus continuidades y transformaciones a través del tiempo. Aunque nuestro actual conocimiento sobre la configuración de Machaquilá en las fases precedentes sólo puede ser fragmentario, sabemos lo suficiente acerca de la asociación entre edificios y pisos de plaza en algunas zonas - particularmente en el caso de las plazas C, G, E y F- como para hacer una reconstrucción tentativa del plano de la ciudad y sus conexiones internas antes de la aparición de rasgos asignados al Clásico Terminal (Figura 12) y calcular sobre esa base los valores manejados en la sección anterior (Cuadro 2).

El conjunto urbano del Clásico Tardío manifiesta ya-como puede observarse en la figura y el cuadro mencionados- el ordenamiento básico que desarrollaría la ciudad en el Terminal. Muestra, no obstante, una menor profundidad global, como consecuencia de la inexistencia del Grupo G-1 y la Plaza F, dentro del complejo palaciego, y del Cuadrángulo, en la Plaza C.

En la zona privada puede señalarse una discrepancia significativa, que viene dada por el mayor tamaño de la Plaza G. Aunque su nivel de profundidad es el mismo en ambas fases, las vías de entrada a ella desde la Plaza C no tenían todavía el obstáculo que supondría la elevación de la Estructura 26 y cabe entender, por tanto, que poseía un acceso menos restringido y mantenía, en términos de facilidad de tránsito, una integración más alta con el área pública de la ciudad. Ello insinúa la posibilidad de que el proceso de cambio durante el Clásico Terminal tendiera hacia una mayor segregación del complejo palaciego y, en consecuencia, hacia una mayor separación entre las ceremonias ligadas a las elites y las dirigidas a una audiencia más amplia. 


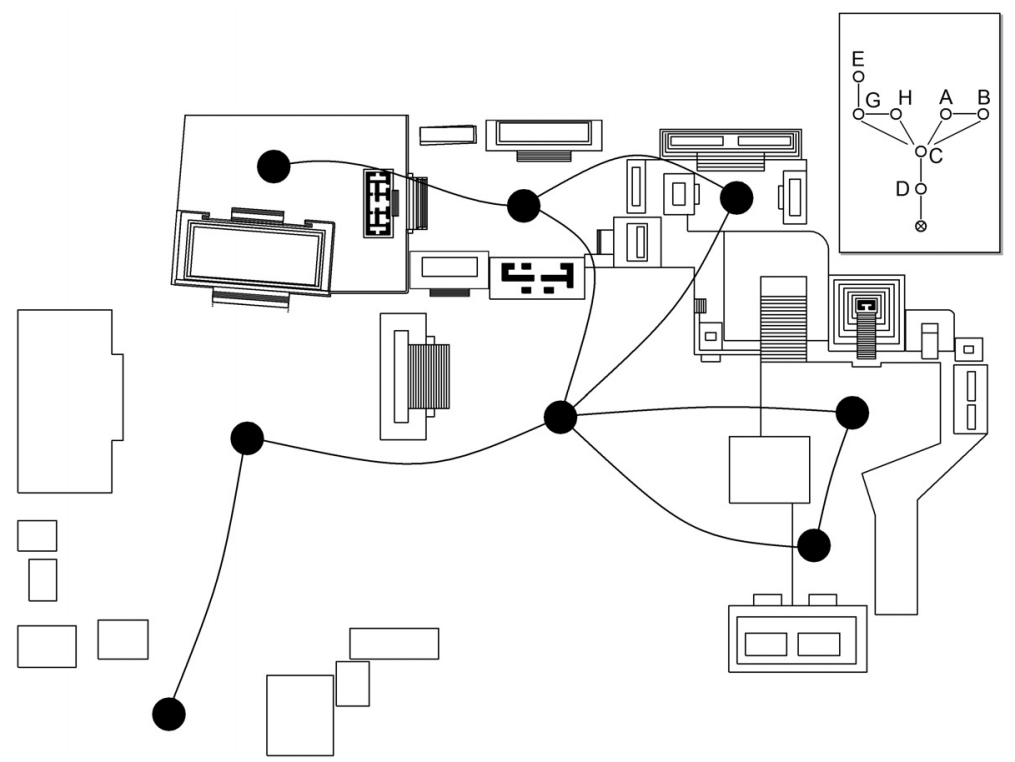

Figura 12: Accesos entre las plazas del área central durante el Clásico Tardío (arriba, a la derecha, se incluye el grafo justificado correspondiente).

Pero es en la zona pública donde se advierten las principales diferencias. Si se asume que el lugar que más tarde ocuparía el Cuadrángulo era un espacio abierto -algo que las excavaciones realizadas no pueden afirmar ni negar-, el tamaño de la Plaza C se eleva hasta hacer de ella la de mayor capacidad, por encima de la Plaza D, y la profundidad de la Plaza B se reduce. Esta configuración subraya la centralidad de la Plaza C como marco de representaciones rituales masivas; aunque la Plaza A se mantuviera separada de ese ámbito, su contigüidad con él y la mayor facilidad de circulación y acceso visual sugieren que esa clase de representaciones abiertas a una audiencia numerosa tendrían una relación más directa con la vertiente dinástica-funeraria que implica la presencia de las estelas y las estructuras de tipo templo asociadas a

Cuadro 2: Accesibilidad y tamaño de las plazas del área central de Machaquilá (Clásico Tardío)

\begin{tabular}{|c|c|c|c|c|c|}
\hline Ámbito & $\begin{array}{l}\text { Profundidad } \\
\text { de acceso }\end{array}$ & $\underset{\left(m^{2}\right)}{\operatorname{Tamaño}}$ & $\begin{array}{c}\text { Capacidad }^{\mathbf{a}} \\
\text { (personas) }\end{array}$ & $\begin{array}{c}\text { (personacidad }^{\mathrm{b}} \\
\text { Capas) }^{2}\end{array}$ & $\begin{array}{c}\text { Asimetría } \\
\text { relativa }\end{array}$ \\
\hline Exterior & 0 & - & - & - & 0,57 \\
\hline Plaza D & 1 & 11.000 & 23.913 & 3.055 & 0,29 \\
\hline Plaza C & 2 & 13.800 & 30.000 & 3.833 & 0,10 \\
\hline Plaza G & 3 & 2.500 & 5.434 & 694 & 0,24 \\
\hline Plaza H & 3 & 1.100 & 2.391 & 305 & 0,29 \\
\hline Plaza A & 3 & 1.800 & 3.913 & 500 & 0,33 \\
\hline Plaza B & 3 & 1.700 & 3.695 & 472 & 0,33 \\
\hline Plaza E & 4 & 2.200 & 4.782 & 611 & 0,52 \\
\hline
\end{tabular}

${ }^{a}$ Estimación basada en una densidad de $0,46 \mathrm{~m}^{2}$ por persona.

${ }^{\mathrm{b}}$ Estimación basada en una densidad de $3,6 \mathrm{~m}^{2}$ por persona. 
ellas. Por consiguiente, la anomalía del divorcio entre los lugares destinados al culto dinástico y los lugares de mayor capacidad de reunión en Machaquilá puede entenderse como algo apuntado ya en la ciudad del Clásico Tardío, pero acentuado en el contexto de dinámicas propias del Clásico Terminal. Su sentido estaría vinculado a un desplazamiento de los rituales masivos hacia los ámbitos de carácter real-administrativo y, como la otra cara de la misma moneda, hacia una creciente restricción de las ceremonias en torno al conjunto ideológico dinástico.

\section{Conclusiones}

Las características culturales que se derivan del estudio arqueológico desarrollado en Machaquilá remiten de manera repetida a su ubicación fronteriza entre dos tradiciones distintas de ámbito regional en las Tierras Bajas Mayas: de un lado, los preceptos culturales desarrollados desde el Preclásico en el Sureste de Petén y, del otro, una orientación hacia la región del río Pasión, fundamentalmente epigráfica pero también presente en la decoración arquitectónica, la escultura y el sistema constructivo.

En diferentes estudios Laporte y sus colaboradores (Laporte, Mejía y Chocón 2005; Laporte, Chocón et al. s.f.) sostienen que Machaquilá mantiene una posición estratégica en una ruta de comunicación que vincula las Montañas Mayas y el Sureste de Petén con el Pasión, el Petexbatún y el Usumacinta; tal posición ventajosa habría permitido que la ciudad participara de características culturales y estilísticas de toda una amplia zona del sur del área maya, desde el este hasta el occidente. En un trabajo anterior, Ciudad y Lacadena (2006) han defendido que el reino de Machaquilá tuvo una antigüedad superior a la que se infiere a partir únicamente de la intervención arqueológica en dicha ciudad; el reino pudo ser fundado a finales del Preclásico Tardío y, con seguridad, era una realidad en el Clásico Temprano. De acuerdo con la información epigráfica, dicho reino habría adoptado una posición beligerante en el amplio conflicto que enfrentó a las ciudades de la órbita política de Calakmul contra las que pertenecían al área de influencia de Tikal; en esa posición, Machaquilá habría sufrido diferentes reveses político-militares en beneficio de Dos Pilas, lo que originó el traslado de su centro político hacia el este y la fundación de la que hoy es la ciudad arqueológica de Machaquilá. El nuevo emplazamiento pudo buscarse en una tierra políticamente poco controlada, quizás escasamente poblada en aquel tiempo (entre 670 y 711 d.C.) - también con escasos recursos naturales- y relativamente alejada de centros políticos poderosos (Laporte, Chocón et al. sf). Quizás esta «tierra de nadie» tuviera también la ventaja de estar situada en la transición entre las dos áreas con tradiciones distintas del sur de las Tierras Bajas mayas anteriormente mencionadas.

Las características de esa fundación, tardía en el tiempo y fruto de una voluntad política de traslado y renacimiento, rigieron el desarrollo de la ciudad y se manifestaron en algunas de las peculiaridades de su plano: su naturaleza compacta, conformando un único núcleo, y la ausencia en él de tipos de conjuntos arquitectónicos vinculados a la idea misma de ciudad en otras capitales del centro y sur de las Tierras Bajas mayas.

Por la propia índole de la intervención arqueológica realizada, no disponemos de una muestra capaz de agotar la caracterización de la arquitectura y el urbanismo de 
Clásico Tardío en Machaquilá. No obstante, los resultados obtenidos sí resultan suficientes para identificar y subrayar como cambios introducidos en el Clásico Terminal los elementos que configuraron la posterior fisonomía de la ciudad -la más visible hoy- y que pueden resumirse en los siguientes puntos:

- Superposiciones masivas, al menos en lo que se refiere a edificios de tipo palacio; este fenómeno se ha detectado de manera similar en otras ciudades que superan el Clásico Tardío y se transforman en centros políticos unitarios: Pueblito, Ixtontón, Ucanal, Ixkún y Calzada Mopán.

- Escalinatas decoradas con grandes cubos arquitectónicos colocados en el entronque con los muros del basamento, que aparecen también en Pueblito y El Chal.

- Uso de sillares bien cortados y pulidos que se insertan en un núcleo de mortero y piedras irregulares, cuya función es menos estructural que la de los utilizados a lo largo del Clásico Tardío. Esta mampostería de revestimiento se ha documentado en El Chal, Ixkún, Calzada Mopán, Ixtontón, Pueblito y Ucanal, asociadas a edificios de Clásico Terminal, y tiene amplia distribución en la península de Yucatán.

- Introducción de nuevos tipos arquitectónicos como el cuadrángulo, muy escaso en el sur de las Tierras Bajas -donde apareció en Pueblito, El Chal y Naranjo-, pero frecuente en el centro y norte de Yucatán.

- Introducción de edificios en forma de C, documentados también en Pueblito en el Clásico Terminal.

- Introducción de un nuevo estilo de decoración arquitectónica, que podría representar un estilo regional durante el Clásico Terminal: se realizó a base de mosaico de piedra, mediante el ensamblaje de pequeños bloques tallados en bajo relieve, para representar rostros de individuos y su ornamentación por medio de tocados, orejeras y otros elementos; se ha documentado también en Ixtontón, Calzada Mopán y Pueblito.

- Uso de columnillas ciegas, en grupos de tres, para decorar los zócalos de los edificios, muy frecuentes en los edificios del centro y norte de Yucatán desde el periodo Clásico Tardío y Clásico Terminal, pero casi ausentes en el sur de las Tierras Bajas mayas.

- Decoración de frisos y cornisas a base de estucos modelados, montados en ocasiones en torno a una estrecha laja de piedra caliza necesaria para dar consistencia a las figuras representadas; si bien presente en Pueblito, se ha encontrado una muestra muy superior en Cancuén y Ceibal, con una técnica muy similar a la empleada en los estucos de Palenque. Se trata de una decoración que quizás podría conformar un estilo regional, esta vez orientado hacia occidente, hacia el Pasión.

- Segregación relativa de los ámbitos destinados al culto dinástico-funerario, insinuada ya en el Clásico Tardío pero aumentada y confirmada en el Terminal, que manifiesta -si se contrasta con otras ciudades clásicas- un cambio en el tipo de rituales destinado a audiencias masivas y, en esa medida, en las formas de legitimación de los gobernantes.

\section{Referencias bibliográficas}

ANDREWS, George F.

1994 Maya Architecture: Basic Forms and Regional Styles. Austin: School of Architecture, University of Texas. 
1995-99 Pyramids and Palaces, Monsters and Masks: the Golden Age of Maya Architecture: the Collected Works of George F. Andrews, 3 vols. Lancaster: Labyrinthos.

Aquino, Daniel E.

2005 «El Cuadrángulo A19: Un conjunto arquitectónico restringido en el epicentro de Naranjo, Petén», en XVIII Simposio de Investigaciones Arqueológicas en Guatemala, 2004., J. P. Laporte, B. Arroyo y H. Mejía, eds., pp. 234-243. Guatemala: Museo Nacional de Arqueología y Etnología.

Barrientos, Tomás, Arthur A. Demarest, Silvia Alvarado, Horacio Martínez, Marc

WOLF y Luis Fernando LuIN

2006 «Hidráulica, ecología, ideología y poder: nueva evidencia y teorías en el Sur de Petén», en XIX Simposio de Investigaciones Arqueológicas en Guatemala, 2005, J. P. Laporte, B. Arroyo y H. Mejía, eds., pp. 319-332. Guatemala: Museo Nacional de Arqueología y Etnología - Asociación Tikal.

BARRIENTOS, Tomás, Rudy LARIOS y Luis F. LuIN

2003 «Investigaciones y conservación en el Patio Sur del Palacio de Cancuen», en XVI Simposio de Investigaciones Arqueológicas en Guatemala, J. P. Laporte, B. Arroyo, H. Escobedo y H. Mejía, eds., pp. 123-134. Guatemala: Museo Nacional de Arqueología y Etnología.

BARrientos, Tomás, Rudy Larios, Alejando SeiJAs y Luis F. Luin

2003 «Investigaciones en la Estructura L7-9, Patio Sur del Palacio de Cancuén», en Proyecto Arqueológico Cancuen. Informe de la temporada 2002, A. Demarest y T. Barrientos, eds., pp. 43-68. Informe presentado en el Instituto de Antropología e Historia, Guatemala.

Bauer, Jeremy R., Ángel Castillo, Daniel Leonard, Mónica Antillón, Antolín VELÁSQUEZ, Jennifer M. JOHNSON y Joel Zovar

2005 «El pasado preclásico y monumental de la región de Holmul: resultados de las temporadas de campo 2003 y 2004 en Cival, Petén», en XVIII Simposio de Investigaciones Arqueológicas en Guatemala, 2004, J. P. Laporte, B. Arroyo y H. Mejía, eds., pp.194-205. Guatemala: Museo Nacional de Arqueología y Etnología.

BAZY, Damien

2010 Relation entre place publique et espaces privés dans les cités mayas de basses terres centrales et méridionales du Préclasique au Classique Terminal. Tesis doctoral inédita. París: Université Paris I.

BECKER, Marshall J.

1982 «Ancient Maya Houses and Their Identification: An Evaluation of Architectural Groups at Tikal and Inferences Regarding Their Functions». Revista Española de Antropología Americana 12: 111-129.

2003 «Plaza Plans at Tikal: A Research Strategy for Inferring Social Organization and Processes of Culture Change at Lowland Maya Sites», en Tikal: Dynasties, Foreigners, and Affairs of State, J. A. Sabloff, ed., pp. 253-280. Santa Fe: School of American Research.

Chocón, Jorge E.

2008 «Excavaciones en la Plaza Noroeste de El Chal, Dolores, Petén», en Exploraciones arqueológicas en cuatro municipios de Petén: Dolores, San Francisco, San Benito y La Libertad, J. P. Laporte, ed., pp. 400-412. Reporte 22. Guatemala: Atlas Arqueológico de Guatemala - Área de Arqueología, Universidad de San Carlos. 
Chocón, Jorge E. y Juan Pedro LAPORTE

2002 «La ciudad de Machaquila», en Reconocimientos y excavaciones arqueológicas en los municipios de Melchor de Mencos, Dolores, Poptun y San Luis, Petén, J. P. Laporte, ed., pp. 1-32. Reporte 16. Guatemala: Ministerio de Cultura y Deporte IDAEH - USAC. (Publicación en CD-ROM.)

2004 «Exploración arqueológica en Pueblito, Municipio de Dolores: el conjunto de tipo Grupo E (Plaza A) y el juego de pelota (Plaza B)», en Reconocimientos y excavaciones arqueológicas en los Municipios de La Libertad, Dolores y Poptun, Petén, J. P. Laporte y H. Mejía, eds., pp. 36-55. Guatemala: Atlas Arqueológico de Guatemala - Área de Arqueología (USAC).

2007 «Hombres en las ruinas: La Acrópolis de Pueblito, Petén», en XX Simposio de Investigaciones Arqueológicas en Guatemala, 2006, J. P. Laporte, B. Arroyo y H. Mejía, eds., pp. 519-560. Guatemala: Museo Nacional de Arqueología y Etnología.

Ciudad Ruiz, Andrés y Jesús AdÁnez PAvón

2006 Comentario a «Plazas, Performers, and Spectators: Political Theaters of the Classic Maya». Current Anthropology 47 (5): 822-823.

Ciudad Ruiz, Andrés, Jesús AdÁnez Pavón y Ma Josefa Iglesias Ponce de León

2006 «La imagen del poder real: las plazas monumentales de Machaquilá». Ponencia presentada en el $52^{\circ}$ Congreso Internacional de Americanistas (Simposio «Lugares y representación: ceremonias comunitarias mayas»). Sevilla, julio de 2006.

Ciudad Ruiz, Andrés y Alfonso LaCAdena García-Gallo

2006 «La fundación de Machaquilá, Petén, en el Clásico Tardío Maya», en Fundación, refundación y relocalización de las ciudades en Mesoamérica y el Mediterráneo antiguo, M. J. Iglesias, R. Valencia y A. Ciudad, eds., pp. 149-180. Madrid: Sociedad Española de Estudios Mayas.

2008 «Procesos históricos de reorientación durante el Clásico Terminal en Machaquilá». Mayab 20: 145-160.

Ciudad Ruiz, Andrés, Alfonso LacAdena, Jesús AdÁnez y Ma Josefa Iglesias

2010 «Espacialidad y ritual en Machaquilá, Petén, Guatemala», en El ritual en el mundo maya: de lo privado a lo público, A. Ciudad, M. J. Iglesias y M. Sorroche, eds., pp. 129-151. Madrid: Sociedad Española de Estudios Mayas - Grupo de Investigación Andalucía-América - CEPHCIS-UNAM.

Demarest, Arthur A.

1992 «Archaeology, Ideology, and Pre-Columbian Cultural Evolution: The Search for an Approach», en Ideology and Pre-Columbian Civilizations, A. Demarest y G. W. Conrad, eds., pp. 1-13. Santa Fe: School of American Research.

Demarest, Arthur A. y Tomás BARrientos

2004 «Los proyectos de arqueología y de desarrollo comunitario en Cancuén: metas, resultados y desafíos en 2003», en XVII Simposio de Investigaciones Arqueológicas en Guatemala, 2007, J. P. Laporte, B. Arroyo, H. Escobedo, y H. Mejía, eds., pp. 473-488. Guatemala: Ministerio de Cultura y Deportes - Instituto de Antropología e Historia - Asociación Tikal.

Demarest, Arthur A. y Tomás Barrientos (eds.)

2001 Proyecto Arqueológico Cancuén: informe de la temporada 2000. Informe entregado al Instituto de Antropología e Historia, Guatemala.

2002 Proyecto Arqueológico Cancuén: informe de la temporada 2001. Informe entre- 
gado al IDAEH, Guatemala.

2003 Proyecto Arqueológico Cancuén: informe de la temporada 2002. Informe entregado al IDAEH, Guatemala.

2004 Proyecto Arqueológico Cancuén: informe de la temporada 2003. Informe entregado al IDAEH, Guatemala.

2005 Proyecto Arqueológico Cancuén: informe de la temporada 2004. Informe entregado al IDAEH, Guatemala.

Demarest, Arthur A., Tomás Barrientos, Melanie Forné, Marc Wolf y Ronald Bishop

2008 «La nueva historia de la puerta a las Tierras Bajas: descubrimientos recientes sobre la interacción arqueología y epigrafía en Cancuén», en XXI Simposio de Investigaciones Arqueológicas en Guatemala, 2002, J. P. Laporte, B. Arroyo, H. Escobedo, y H. Mejía, eds., pp. 515-531. Guatemala: Ministerio de Cultura y Deportes - Instituto de Antropología e Historia - Asociación Tikal.

GARCÍA, José Luis

1976 Antropología del territorio. Madrid: Taller Ediciones JB.

GENDROP, Paul

1983 Los estilos de Río Bec, Chenes y Puuc en la arquitectura maya. México: Universidad Nacional Autónoma de México.

GRAHAM, Ian

1967 Explorations in El Peten, Guatemala. Middle American Research Institute Publication 33. Nueva Orleans: Tulane University.

HARRISON, Peter D.

2003 «Palaces of the Royal Court at Tikal», en Maya Palaces and Elite Residences: An Interdisciplinary Approach, J. J. Christie, ed., pp. 98-119. Austin: University of Texas Press.

HILLIER, Bill y Julienne HANSON

1984 The Social Logic of Space. Cambridge: Cambridge University Press.

Houston, Stephen D. (ed.)

1998 Function and Meaning in Classic Maya Architecture. Washington: Dumbarton Oaks Research Library and Collection.

Iglesias Ponce de LeÓn, Ma Josefa y Alfonso LaCAdena García-Gallo

2003 «Nuevos hallazgos glíficos en la Estructura 4 de Machaquila, Petén, Guatemala». Mayab 16: 65-71.

INOMATA, Takeshi

2006 «Plazas, Performers, and Spectators: Political Theaters of the Classic Maya». Current Anthropology 47 (5): 805-842.

InOMATA, Takeshi, Daniela TRIADAN y Otto Rodrigo Román

2010 «La transformación y continuidad de ritos durante el período Preclásico en Ceibal, Guatemala», en El ritual en el mundo maya: de lo privado a lo público, A. Ciudad, M. J. Iglesias y M. Sorroche, eds., pp. 29-48. Madrid: Sociedad Española de Estudios Mayas - Grupo de Investigación Andalucía-América - CEPHCIS-UNAM

Just, Bryan R.

2002 «Ninth-Century Stelae of Machaquilá and Seibal». Informe presentado a FAMSI. Documento electrónico, <http://www.famsi.org/reports/01050/index.html >, con 
acceso el 15/12/2010.

LACADENA García-Gallo, Alfonso

2006 «Excavaciones en Machaquilá. Temporada 2005: El recinto cuadrilobulado de la Plaza A», en Exploraciones arqueológicas en el sureste y centro-oeste de Petén, J. P. Laporte y H. Mejía, eds., pp. 74-123. Reporte 20. Guatemala: Atlas Arqueológico de Guatemala - Área de Arqueología de la Universidad de San Carlos.

Lacadena García-Gallo, Alfonso y Ma Josefa Iglesias Ponce de León

2005 «Una relación epigráfica relacionada con la Estructura 4 de Machaquilá», en XVIII Simposio de Investigaciones Arqueológicas en Guatemala, 2004, J. P. Laporte, B. Arroyo y H. Mejía, eds., pp. 677-690. Guatemala: Museo Nacional de Arqueología y Etnología - Asociación Tikal.

2006 «La recreación del espacio mítico de la Montaña de las Flores en un palacio de Machaquilá, Petén», en XIX Simposio de Investigaciones Arqueológicas en Guatemala, 2005, J. P. Laporte. B. Arroyo y H. Mejía, eds., pp. 589-599. Guatemala: Ministerio de Cultura y Deportes - Instituto de Antropología e Historia - Asociación Tikal.

LAPORTE, Juan Pedro

s.f. «Asentamiento y entidades políticas del Clásico Terminal en la cuenca del río Mopan, Petén, Guatemala». Manuscrito en posesión de los autores.

LAPORTE, Juan Pedro (ed.)

2001 Machaquila, Poptun, Petén: la ciudad y el asentamiento prehispánico regional. Informe entregado a Ahau Foundation. Guatemala: Atlas Arqueológico de Guatemala.

Laporte, Juan Pedro, Jorge E. Chocón, Héctor E. MeJía y Heidy QueZadA

s.f. «La cuenca del río Machaquilá: el asentamiento prehispánico del límite sureste de Petén en Guatemala». Manuscrito en preparación para su publicación en Mexicon (inconcluso).

LAPORTE, Juan Pedro y Héctor E. MejíA

2002 «Tras la huella del mopan: arquitectura del Clásico Terminal y del Postclásico en el Sureste de Petén», en XV Simposio de Investigaciones Arqueológicas en Guatemala, 2001, J. P. Laporte, H. Escobedo y B. Arroyo, eds., pp. 65-96. Guatemala: Museo Nacional de Arqueología y Etnología.

LAPORTE, Juan Pedro, Héctor E. MeJíA y Jorge E. CHOCóN

2005 «Machaquilá en una perspectiva geográfica regional», en XVIII Simposio de Investigaciones Arqueológicas en Guatemala, 2004, J. P. Laporte, B. Arroyo y H. Mejía, eds., pp.400-417. Guatemala: Museo Nacional de Arqueología y Etnología.

LAPORTE, Juan Pedro, Paulino Morales y Mariana VAldizón

1997 «San Luis Pueblito: un sitio mayor al oeste de Dolores, Petén». Mexicon 19 (3): 47-51.

LIENDO STUARDO, Rodrigo

2003 «Access Patterns in Maya Royal Precints», en Maya Palaces and Elite Residences: An Interdisciplinary Approach, J. J. Christie, ed., pp. 184-203. Austin: University of Texas Press. 
Love, Michael, Julia Guernsey, Sheryl Carcuz y Molly Morgan

2006 «El Monumento 3 de La Blanca: Una Nueva Escultura del Preclásico Medio», en XIX Simposio de Investigaciones Arqueológicas en Guatemala, 2005, J. P. Laporte, B. Arroyo y H. Mejía, eds., pp. 56-69. Guatemala: Museo Nacional de Arqueología y Etnología - Asociación Tikal.

MOORE, Jerry D.

1996a Architecture and Power in the Ancient Andes: The Archaeology of Public Buildings. Cambridge: Cambridge University Press.

1996b «The Archaeology of Plazas and the Proxemics of Ritual: Three Andean Traditions». American Anthropologist 98 (4): 789-802.

Morales, Paulino

1995 El Chal, un sitio arqueológico asentado en la sabana del Petén central: una aproximación a su asentamiento. Guatemala: Universidad de San Carlos.

Morales, Paulino y Juan Pedro LAPORTE

1995 «El Chal: un sitio en la sabana de Dolores, Petén». Mexicon 17 (3): 44-49.

Pollock, Harry E. D.

1980 The Puuc: An Archaeological Survey of the Hill Country of Yucatan and Northern Campeche, Mexico. Memoirs of the Peabody Museum of Archaeology and Ethnology, vol. 19. Cambridge: Harvard University.

Ponciano, Erick M., Takeshi Inomata, Daniela Triadan, Estela Pinto, Jessica Munson y

Omar SCHWENDENER

2007 «Revisitando Ceibal: Cambios sociales durante el Preclásico y Clásico Terminal en la región del Pasión», en XX Simposio de Investigaciones Arqueológicas en Guatemala, 2006, J. P. Laporte, B. Arroyo y H. Mejía, eds., pp. 448-463. Guatemala: Museo Nacional de Arqueología y Etnología.

Quezada, Heidy, Jorge E. Chocón, Mario VÁzquez y Juan Pedro Laporte

1998 «Nuevas exploraciones en El Chal, municipios de Dolores y Santa Ana», en Reconocimientos y excavaciones arqueológicas en los municipios de Santa Ana, Melchor de Mencos y Dolores, J. P. Laporte, ed., pp. 1-53. Reporte 12. Guatemala: Atlas Arqueológico de Guatemala - Área de Arqueología (USAC).

SÁNCHEZ, Julia

2005 «Ancient Maya Royal Strategies: Creating Power and Identity Through Art». Ancient Mesoamerica 16: 261-275.

SMith, A. Ledyard

1982 «Major Architecture and Caches», en Excavations at Seibal, G. R. Willey, ed., pp. 1-263. Memoirs of the Peabody Museum of Archaeology and Ethnology, vol. 15 (1). Cambridge: Harvard University.

Triadan, Daniela y Juan Manuel PALOmo

2010 «Estrategias políticas en el Clásico Terminal en Ceibal», en XXIII Simposio de Investigaciones Arqueológicas en Guatemala, 2009, B. Arroyo, A. Linares y L. Páiz, eds., pp. 251-264. Guatemala: Museo Nacional de Arqueología y Etnología.

VALDIZÓN, Mariana

1995 Reconocimiento en la cuenca del río Poxte, Petén: un acercamiento a la organización política del área. Tesis de licenciatura. Universidad de San Carlos de Guatemala. 
VALENZUELA, Claudia

2006 «El Grupo 25 de Pueblito, Dolores: Un cuadrángulo menor junto a la Calzada del Eje en el sector sur de la ciudad», en Exploraciones arqueológicas en el sureste y centro-oeste de Petén, J. P. Laporte y H. Mejía, eds., pp. 257-275. Reporte 20. Guatemala: Atlas Arqueológico de Guatemala - Área de Arqueología de la Universidad de San Carlos.

WEBSTER, David L.

1998 «Classic Maya Architecture: Implications and Comparisons», en Function and Meaning in Classic Maya Architecture, S. D. Houston, ed., pp. 5-47. Washington: Dumbarton Oaks Research Library and Collection.

WILlEy, Gordon R. y A. Ledyard SMITH

1967 «A Temple at Seibal, Guatemala». Archaeology 20 (4): 290-298. 